\title{
RAPID DIGITALIZATION
}

\author{
BY \\ WILLIAM EVANS, PETER DICK,* AND BYRON EVANS
}

From the Cardiac Department of the London Hospital

Received February 14, 1948

When it has been decided to give digitalis to a patient with heart failure, the need for inducing its effects quickly (rapid digitalization) is sometimes evident. There is no unanimity on the best preparation to use for this purpose nor on the best way to give the preparation of choice. Mackenzie (1914) said that he seldom failed to induce rapid digitalis effect by giving the drug by mouth, but occasionally in auricular fibrillation when the heart rate exceeded 140 a minute he had found that strophanthin $(1 / 125$ grain) intravenously reduced the rate and relieved symptoms in five to eight hours. From his own observation he saw no reason to give preference to any preparation, but he pointed out the need to investigate this problem. In 1925 Cushny again stressed the necessity to examine the comparative value of digitalis preparations.

There is available a comparison of series of patients on different drugs with a digitalis effect, but the relative value of two or three preparations in the same patient has seldom been reported. The present clinical trial was designed to discover the most effective preparation for rapid digitalization when given orally or intravenously, by comparing the effect of as many preparations as possible in the same patient and under the same conditions. This procedure does not appear to have been adopted for rapid digitalization as it has been done in the case of maintenance therapy (Evans, 1940).

It was decided to test the following drugs as likely to prove of value: strophanthin, ouabain and $\mathrm{k}$-strophanthosid, digoxin, digitoxin, lanatoside $\mathrm{C}$, digitalis leaf, and the tincture of digitalis. In addition, certain remedies like coramine and cardiazol were given to certain cases as a control. In order that the results might be comparable it was necessary to give a full dose of each drug. In the earlier cases varying doses of some preparations were tried and in certain instances doses considerably larger than those recommended were used. The relative value of these preparations was studied in 20 patients.

The most satisfactory index of digitalization is the fall in the ventricular rate in auricular fibrillation and this was used, but improvement in the objective signs of failure was also observed and so was the diuretic response. Because no digitalis preparation was to be given between the testing of each individual preparation, cases with severe heart failure could not be used. Cases of rapid auricular fibrillation with slight or moderate congestive heart failure, were selected. The patients had mitral stenosis, occasionally combined with aortic incompetence, or had hypertension. They were confined to bed on a normal hospital diet and fluids were restricted. The fluid intake and urinary output were measured. The apical rate was particularly recorded and any change in the signs of heart failure was looked for. The majority received no other treatment, apart from sedatives when necessary, but in a few with moderate œdema mercurial diuretics were not withheld; they were not given during the testing period for the separate digitalis preparations nor on the preceding day. After a few days of preliminary observation, and after ensuring that no digitalis had been given during the previous seven days, the first preparation was given. The apical rate was counted over three consecutive half minutes; the respiration and blood pressure were also noted. The drug was then given, and the heart rate was counted for three consecutive half-minute periods every quarter of an hour, until it had ceased to fall over a period of one and a half to two hours. It was found in practice that the fall was almost always complete within four hours. Symptoms and signs of toxicity were sought. Subjective and objective signs of improvement were noted during the following forty-eight hours although a noticeable change was not found because of the relative freedom from symptoms

* This work formed the basis of a thesis submitted by P.D. and accepted for the M.D. Degree of the University of Cambridge. 
shown by the selected cases while at rest in bed. A conspicuous diuretic response seldom resulted in these patients with only slight heart failure, and it was too erratic to be accepted as a measure of the benefit. Reliance was placed on the heart rate as a criterion of improvement in the selected cases, during a short period following the administration of a particular digitalis preparation.

The following is an example of how each trial was recorded.
This experimental error, with a variation between the first and second preparation greater than between succeeding preparations, was never great, and was partly overcome by giving the preparations in a different order to each patient, a practice always adopted. The number of tests that it was possible to carry out in each case was thus limited by the failure of the ventricular rate to rise to a comparable level after a variable number of tests. In several cases after the first preparation it did not rise suffi-

Name : C. J. S. Age : 31. Date : 22/11/45.

Diagnosis and Summary : Mitral stenosis, auricular fibrillation, and heart failure.

Observation : Effect of $3 \mathrm{mg}$. digoxin given orally.

\begin{tabular}{|c|c|c|c|c|}
\hline Time & Ventricular rate & Respiratory rate & Blood pressure & Remarks \\
\hline $\begin{array}{l}10.30 \text { a.m. } \\
10.45 \text { a.m. } \\
11.0 \text { a.m. } \\
11.15 \text { a.m. } \\
11.30 \text { a.m. } \\
11.45 \text { a.m. } \\
12.0 \text { p.m. } \\
12.15 \text { p.m. } \\
12.30 \text { p.m. } \\
12.45 \text { p.m. } \\
1.0 \text { p.m. } \\
1.15 \text { p.m. } \\
1.30 \text { p.m. } \\
1.45 \text { p.m. } \\
2.0 \text { p.m. } \\
2.15 \text { p.m. } \\
2.30 \text { p.m. } \\
2.45 \text { p.m. } \\
3.0 \text { p.m. } \\
3.15 \text { p.m. } \\
3.30 \text { p.m. } \\
3.45 \text { p.m. } \\
4.0 \text { p.m. } \\
4.15 \text { p.m. } \\
4.30 \text { p.m. } \\
4.45 \text { p.m. } \\
5.0 \text { p.m. } \\
5.15 \text { p.m. } \\
5.30 \text { p.m. } \\
6.0 \text { p.m. } \\
8.0 \text { p.m. } \\
\text { 23.11.45 } \\
8 \text { a.m. }\end{array}$ & $\begin{array}{r}140.134 .146 \\
142.130 .130 \\
114.128 .126 \\
124.130 .132 \\
140.138 .124 \\
116.116 .116 \\
130.120 .116 \\
104.108 .108 \\
120.110 .110 \\
116.106 .110 \\
118.98 .106 \\
98.98 .106 \\
100.88 .94 \\
96.92 .92 \\
104.86 .92 \\
84.80 .84 \\
86.84 .92 \\
82.76 .74 \\
74.80 .76 \\
74.84 .80 \\
76.74 .74 \\
\text { 74. } 80.94 \\
\text { 86. 86. } 84 \\
80.80 .88 \\
78.80 .82 \\
88.84 .80 \\
80.84 .78 \\
80.78 .76 \\
76.80 .80 \\
80.84 .80 \\
\\
74.72 .68\end{array}$ & $\begin{array}{l}14 \\
14 \\
14\end{array}$ & $\begin{array}{l}120 / 80 \\
115 / 70 \\
110 / 75 \\
110 / 70 \\
110 / 75 \\
110 / 75 \\
120 / 80\end{array}$ & $\begin{array}{l}\text { Digoxin } 3.0 \text { mg. given orally. } \\
\text { Had dinner } 12.20 \text { p.m. Onset of nausea; } \\
\text { unable to eat pudding. } \\
\text { Very nauseated. } \\
\text { Nausea less. } \\
\text { Nausea completely gone. }\end{array}$ \\
\hline
\end{tabular}

The patient received no further digitalis for a period of three to fourteen days, until the ventricular rate had returned to its previous level and the effects of the previous preparation had worn off. The length of time varied with the different preparations. On many occasions the ventricular rate did not return exactly to its previous rate, tending to settle at a lower level after a trial with each preparation. ciently for a fair comparison to be made with succeeding preparations and such were excluded from the series. For this reason it proved difficult to collect a series of suitable patients for this investigation.

\section{RESULTS}

The criterion adopted for the effectiveness of a preparation has been the fall in heart rate produced 
by it. The results are summarized in the form of graphs showing this fall in heart rate. The fall shown at each time period is an average of the preceding half-hour or hour's readings, deducted from the average initial rate before the administration of the drug, and thus represents the effect of the drug during the preceding half-hour or hour. They are arranged usually in the order of effectiveness, and not in the order the drugs were given, for this was deliberately varied.

The extent of the fall in heart rate produced by a digitalis preparation has been shown to be closely related to the initial heart rate (Lyon and Gilchrist, 1927), as would be expected. The tendency of the heart rate to fall throughout the periods of trial in most cases, coinciding with the improvement of heart failure, has already been mentioned. It is seldom possible to simulate laboratory conditions in a clinical investigation, and it could not be anticipated that any patient would be in exactly the same state prior to the administration of each preparation. The consistency of action of a drug in the same dosage and in the same patient was tested in two cases. In one case, receiving $1.5 \mathrm{mg}$. of digoxin by mouth on two occasions with a week's interval, although the initial heart rate was almost identical in both trials, the effect was different whereas in another case the effect was almost identical (Fig. 1). On the whole drugs were found that will produce a full digitalis effect is known to vary a great deal in different patients, a fact that was apparent in these trials. With the lesser doses, unless a satisfactory therapeutic action had taken place, there was no certainty that the patient had received what was for him a full dose of that preparation, and the result could not, therefore, be fairly compared with the action of another preparation. For the purpose of comparison of the different drugs, a minimum full dose was chosen for each preparation, based partly on the result of these trials and partly on previous experience. A further difficulty was the variability in the time taken to induce proper digitalization in relation to the size of the dose when given by mouth. With large doses, such as $3 \mathrm{mg}$. of digoxin by mouth, an effect was seen more rapidly than with smaller doses, although the final effect might be the same. It was occasionally noticed with oral administration that the full effect was not seen within four hours, so that when comparing two drugs the results observed within four hours might reflect the dosage rather than the effectiveness of the preparation. With intravenous therapy the maximal effect was invariably seen within four hours and comparison with an oral preparation might on that account be open to the same fallacy at times.

As this study was undertaken to ascertain the best preparations for rapid digitalization some time-

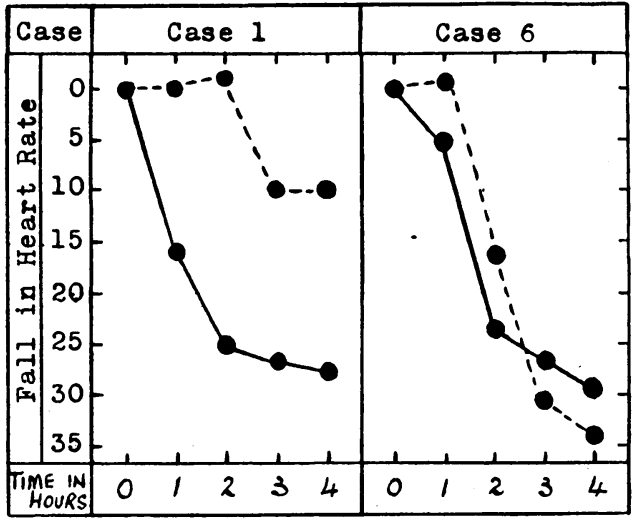

FIG. 1.-Comparing the effects of repeated digitalis medication in the same patient. In Case 1 the effect of $1.5 \mathrm{mg}$. of digoxin by mouth was not the same, but in Case 6 the effect of $2.0 \mathrm{mg}$. of digoxin by mouth was identical on each occasion. Continuous and discontinuous lines represent separate trials with one week's interval.

to reproduce the same result with remarkable consistency in successive cases.

A further difficulty was the determination of the size of the dose for each patient. The amount

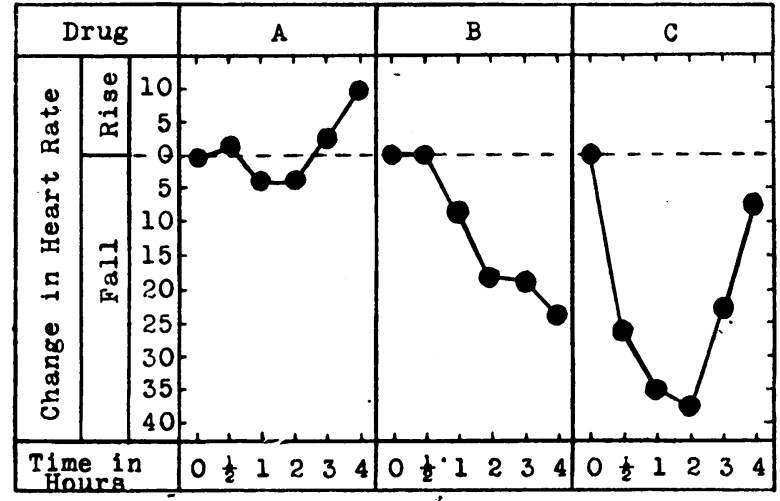

FIG. 2.-Rapid digitalization in a man aged 60 with hypertension and auricular fibrillation. (A) Digitaline (Nativelle), $2.0 \mathrm{mg}$. by mouth. (B) Digoxin, $2.0 \mathrm{mg}$. by mouth. (C) K-Strophanthosid, $0.5 \mathrm{mg}$. intravenously.

limit had to be applied within which the effect would be regarded as rapid. Four hours was selected as a suitable period for it represents the time which may be regarded as maximal in a patient requiring rapid digitalization. The comparison of results, therefore, has been based entirely on a preparation's effectiveness within that period. 
In giving the results each drug is considered in turn and its effectiveness judged in each patient. A digitalis effect was classified as good when the fall in heart rate within four hours was 75 per cent of the maximal fall produced by any preparation in that patient, moderate between 50 and 75 per cent, and slight below 50 per cent. This method of assessing the therapeutic effect was possible, as an optimum result was produced in all patients, with the exception of one, by at least one preparation. The results are summarized in the form of a Table for each drug, showing the number of times it was more, equally, or less effective than the others, within two and within four hours. The effect of two preparations was regarded as equal if the difference in the fall of the heart rate was not more than 5 per cent of the maximum produced by any drug in that patient. Tables 1 to 7 show the number of times each preparation proved more effective than the other, but they do not show the relative differences. Table 8 shows the consistency of effectiveness of each drug in different doses. The actual change in the heart rate from different preparations in the same patient is shown in Fig. 2 to 20.

Other remedies. These were introduced solely for the purpose of controlling the results obtained from the use of active preparations.

Coramine (Nikethamidum B.P.), described as a respiratory and vasomotor stimulant, was given once in a dose of $1.7 \mathrm{ml}$. and four times in a dose of $3.4 \mathrm{ml}$. of a 25 per cent solution intravenously. In one case its administration was followed by momentary dizziness, but no other effect was noted and there was no significant change in the heart rate.

Cardiozol (Leptazolum B.P.), a convulsant in large doses, and stated to be a respiratory and vasomotor stimulant in smaller doses, was given to two cases in a dose of $2 \mathrm{ml}$. intravenously. In one case the rate rose from 100 to 105 during the first five minutes and remained at about this level for the first hour, but during the second hour it averaged 125. In another the injection was followed by a sensation of dizziness lasting eight minutes. The heart rate rose from 105 to 140 .

Analeptic preparation 3067/16 (Roche) was given intravenously once. Two minutes later the patient experienced severe dizziness and mental excitement which passed off gradually. A slight rise in the heart rate took place.

Cycliton was given once in a dose of $2 \mathrm{ml}$. intravenously. The heart rate rose sharply following the injection.

\section{Strophanthin}

Strophanthin was given intravenously 6 times in a dose of 1/100 gr. (0.65 g.) and 4 times in a dose of $1 / 60 \mathrm{gr}$. (1.08 mg.). In a dose of $1 / 100 \mathrm{gr}$. it had a good effect once, a slight effect once, and practically none in another. In two cases a sharp fall in the heart rate occurred during the first hour, but it had risen to its previous level by the fourth hour. In one case it was followed by a slight rise in rate. In a dose of 1/60 gr. it had a good effect three times, and a slight effect once. No toxic effects were seen. From previous reports $0.5 \mathrm{mg}$. is generally regarded as the maximal safe dose, and this, therefore, was considered to be a full dose for the purpose of comparison. It was compared with ouabain intravenously 3 times, strophosid intravenously 3 times, digalen intravenously twice, digoxin by mouth 14 times, digoxin intravenously 10 times, digitaline (Nativelle) by mouth once, and lanatoside $\mathrm{C}$ intravenously 3 times. The results are shown in Table I.

TABLE I

The Effect of Strophanthin intravenously Compared with that of Other Preparations

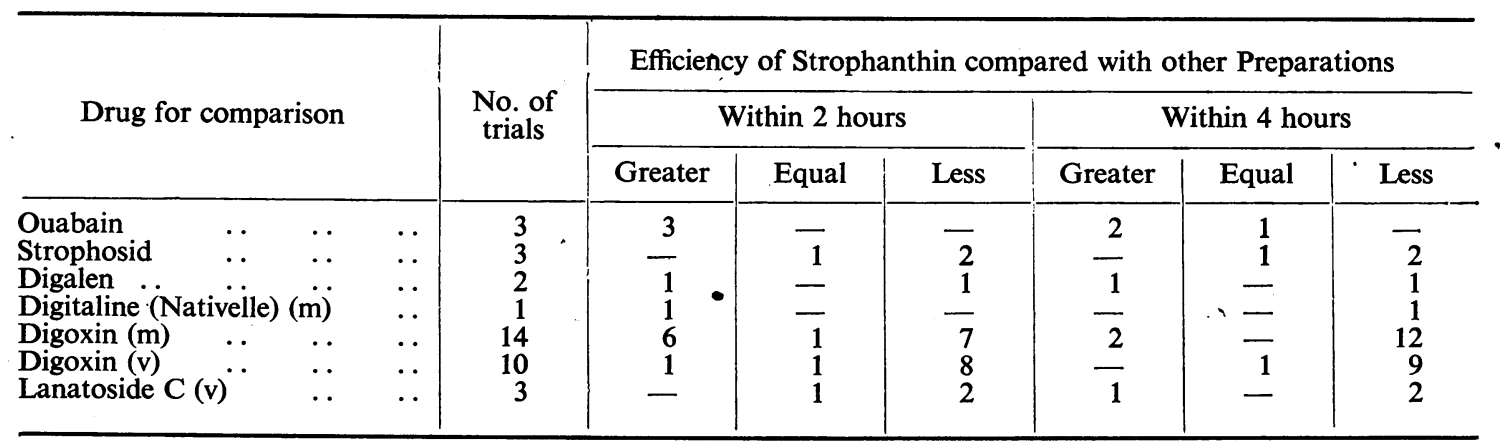

In this and in other tables $(\mathrm{m})$ indicates that the preparation was given by mouth and (v) intravenously. 


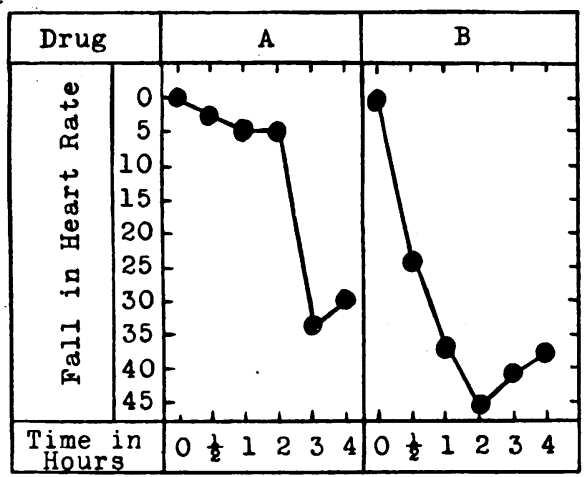

FIG. 3.-Rapid digitalization in a woman aged 61 with mitral stenosis and auricular fibrillation. (A) Digitaline (Nativelle), $1 \cdot 75$ mg. by mouth. (B) Lanatoside C, 1.2 mg. intravenously.

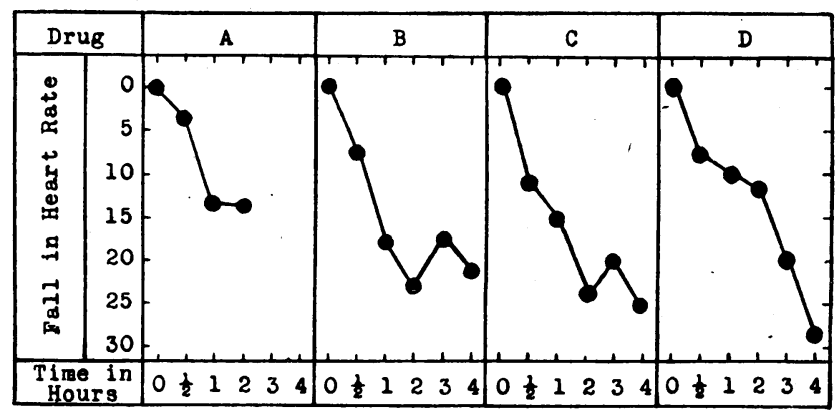

FIG. 4.- Rapid digitalization in a man aged 54 with hypertension and auricular fibrillation. (A) Digoxin, $1.5 \mathrm{mg}$. by mouth. (B) Digoxin, $1.5 \mathrm{mg}$. intravenously. (C) Lanatoside C, $1.5 \mathrm{mg}$. intravenously. (D) Digitaline (Nativelle), $1.2 \mathrm{mg}$. intravenously.

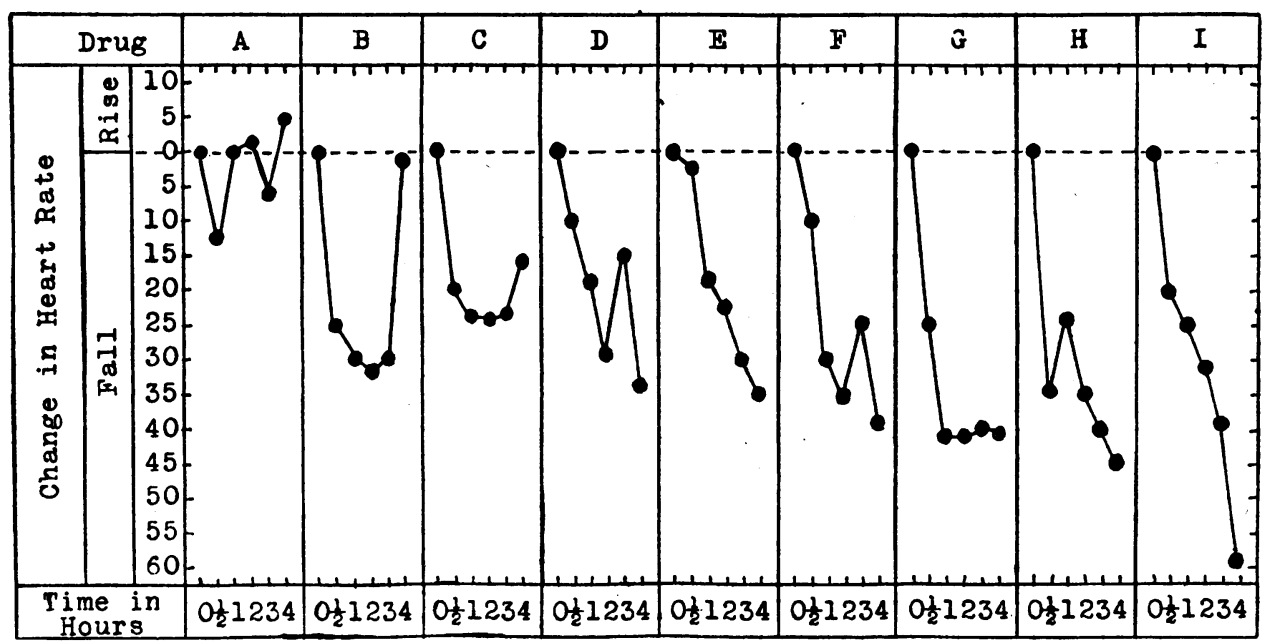

FIG. 5.-Rapid digitalization in a woman with mitral stenosis and auricular fibrillation. (A) Coramine, $3.4 \mathrm{ml}$. intravenously. (B) Lanatoside C, 1.0 mg. by mouth. (C) Lanatoside C, $1 \mathrm{mg}$. intravenously. (D) K-Strophanthosid, $1 \mathrm{ml}$. intravenously. (E) Strophanthin, 1/60 gr. intravenously. (F) Digoxin, $2.0 \mathrm{mg}$. by mouth. (G) Digoxin, $1.5 \mathrm{mg}$. intravenously. (H) Digalen, $1 \mathrm{ml}$. intravenously. (I) Digoxin, $3.0 \mathrm{mg}$. by mouth.

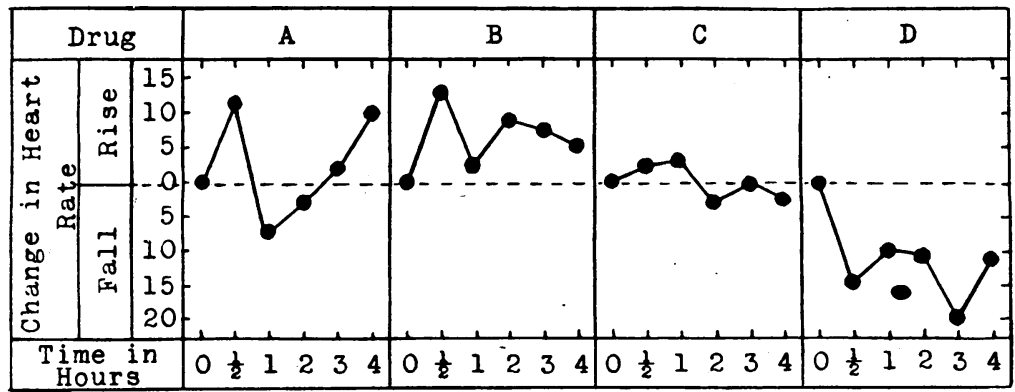

FIG. 6.-Rapid digitalization in a man with hypertension and auricular fibrillation. (A) Analeptic 3067/16 (Roche), 2 ampoules intravenously. (B)

Cardiazol, $2 \mathrm{ml}$. intravenously. (C) Coramine, $3.4 \mathrm{ml}$. intravenously. (D) Tincture of digitalis, 2 drachms by mouth. 


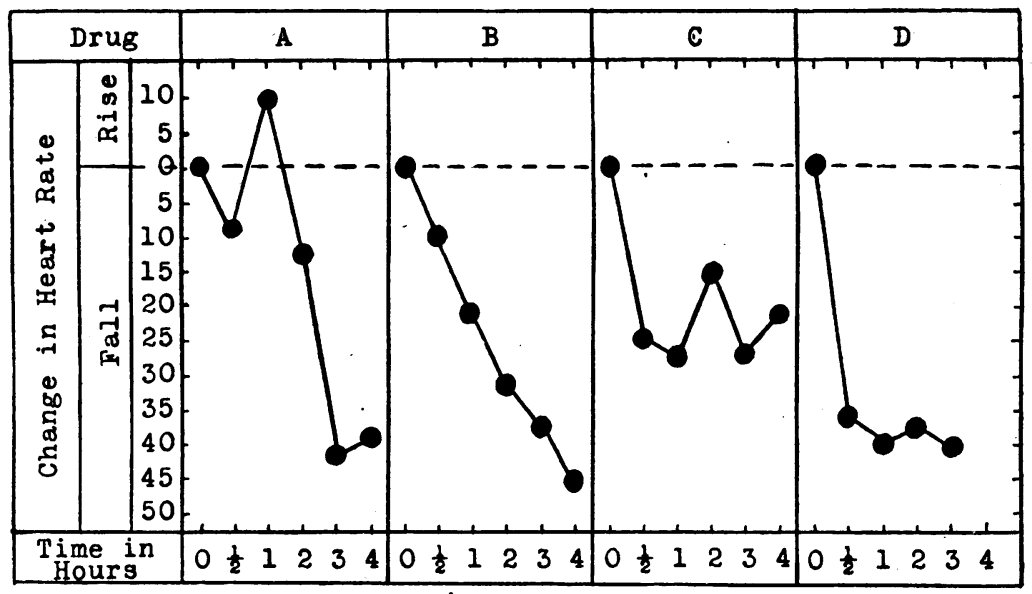

FIG. 7.-Rapid digitalization in a woman aged 37 with mitral stenosis and auricular fibrillation. (A) Digoxin, $1.5 \mathrm{mg}$. by mouth. (B) Digitaline (Nativelle), $2.0 \mathrm{mg}$. by mouth. (C) Lanatoside C, $3.0 \mathrm{mg}$. by mouth. (D) K-Strophanthosid, $0.5 \mathrm{mg}$. intravenously.

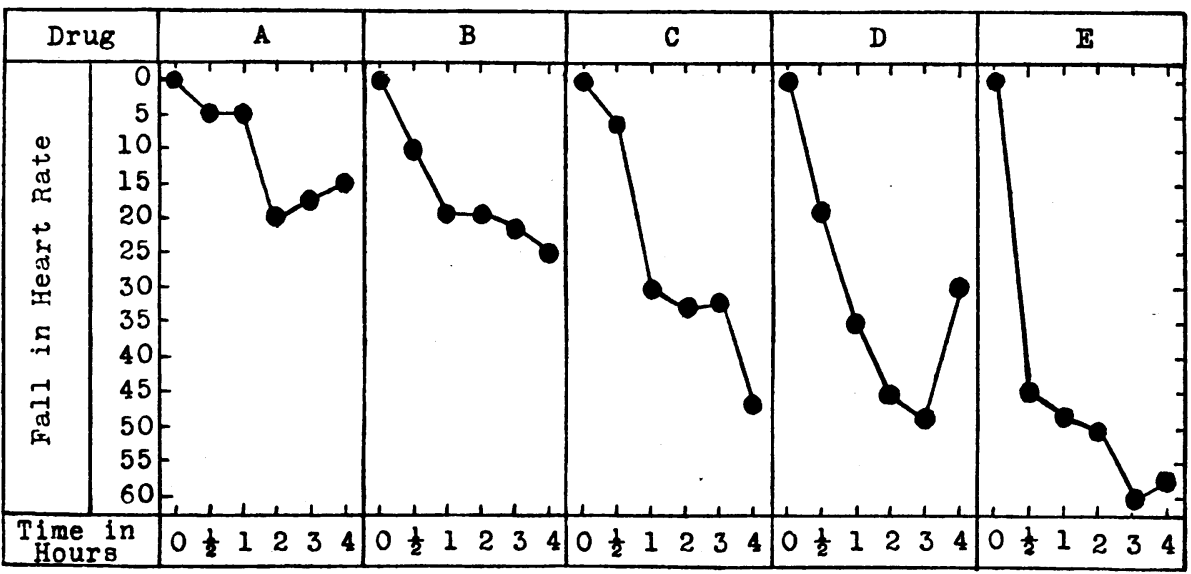

FIG. 8.-Rapid digitalization in a woman aged 57 with hypertension and auricular fibrillation. (A) Digitaline (Nativelle), 1.25 mg. by mouth. (B) Digoxin, $1.25 \mathrm{mg}$. by mouth. (C) Digitaline (Nativelle), 1.2 mg. intravenously. (D) Digoxin, $1.25 \mathrm{mg}$. intravenously. Lanatoside C, $1.5 \mathrm{mg}$. intravenously.

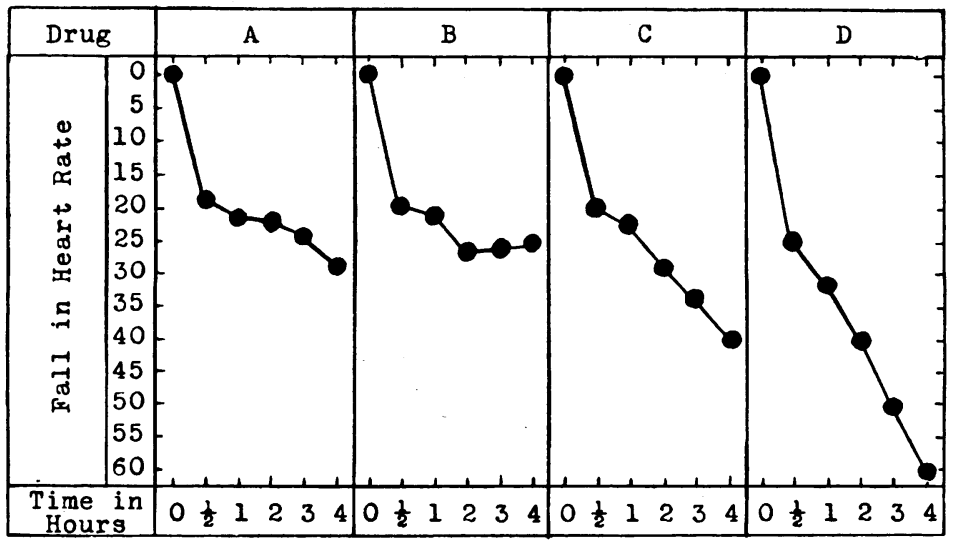

FIG. 9.--Rapid digitalization in a woman aged 48 with mitral stenosis, aortic incompetence, and auricular fibrillation. (A) Digoxin, $1.5 \mathrm{mg}$. intravenously. (B) Digitaline (Nativelle), $1.5 \mathrm{mg}$. intravenously. (C) Digitaline (Nativelle), $1.5 \mathrm{mg}$. by mouth. (D) Lanatoside C, $1.5 \mathrm{mg}$. intravenously. 


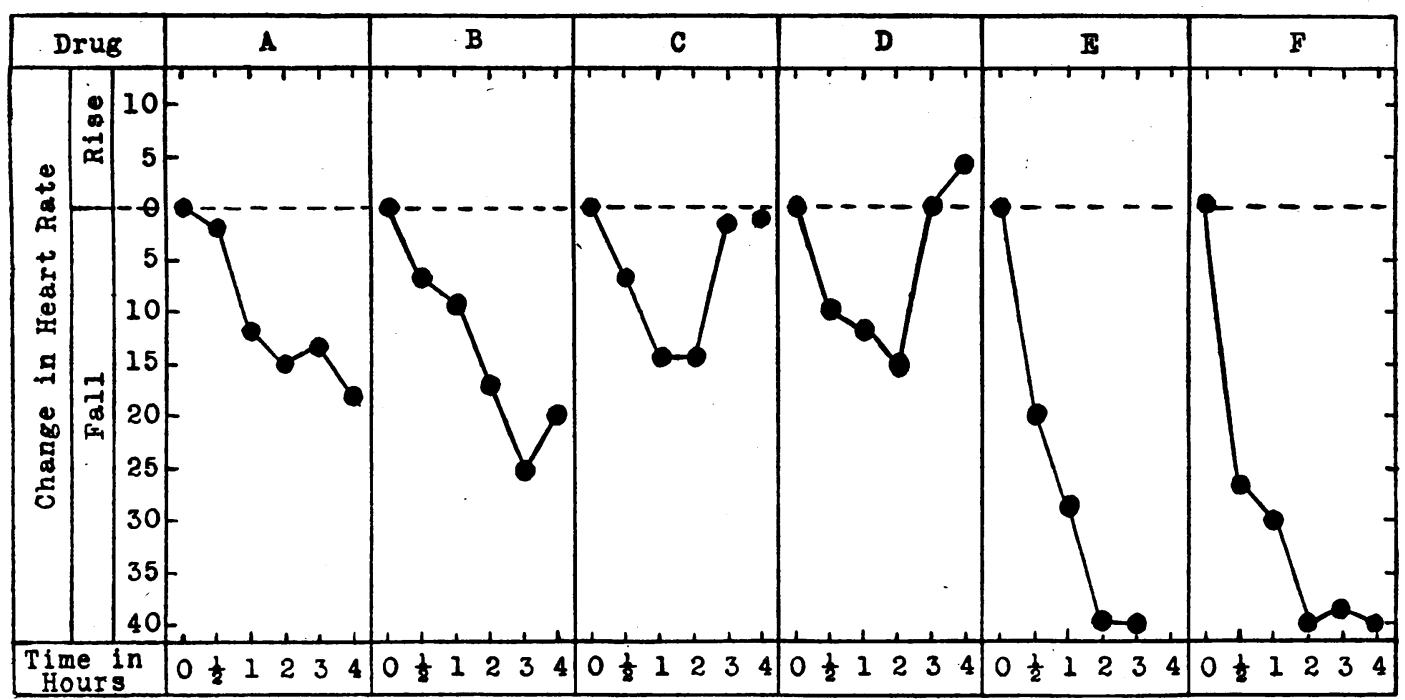

Fig. 10.-Rapid digitalization in a man aged 29 with mitral stenosis and auricular fibrillation. (A) KStrophanthosid, $0.5 \mathrm{mg}$. intravenously. (B) Digitaline (Nativelle), $2.0 \mathrm{mg}$. by mouth. (C) Digoxin, $2.0 \mathrm{mg}$. by mouth. (D) Lanatoside C, $3.0 \mathrm{mg}$. by mouth. (E) Lanatoside C, $1.5 \mathrm{mg}$. intravenously. (F) Digitaline (Nativelle), $1.5 \mathrm{mg}$. intravenously.

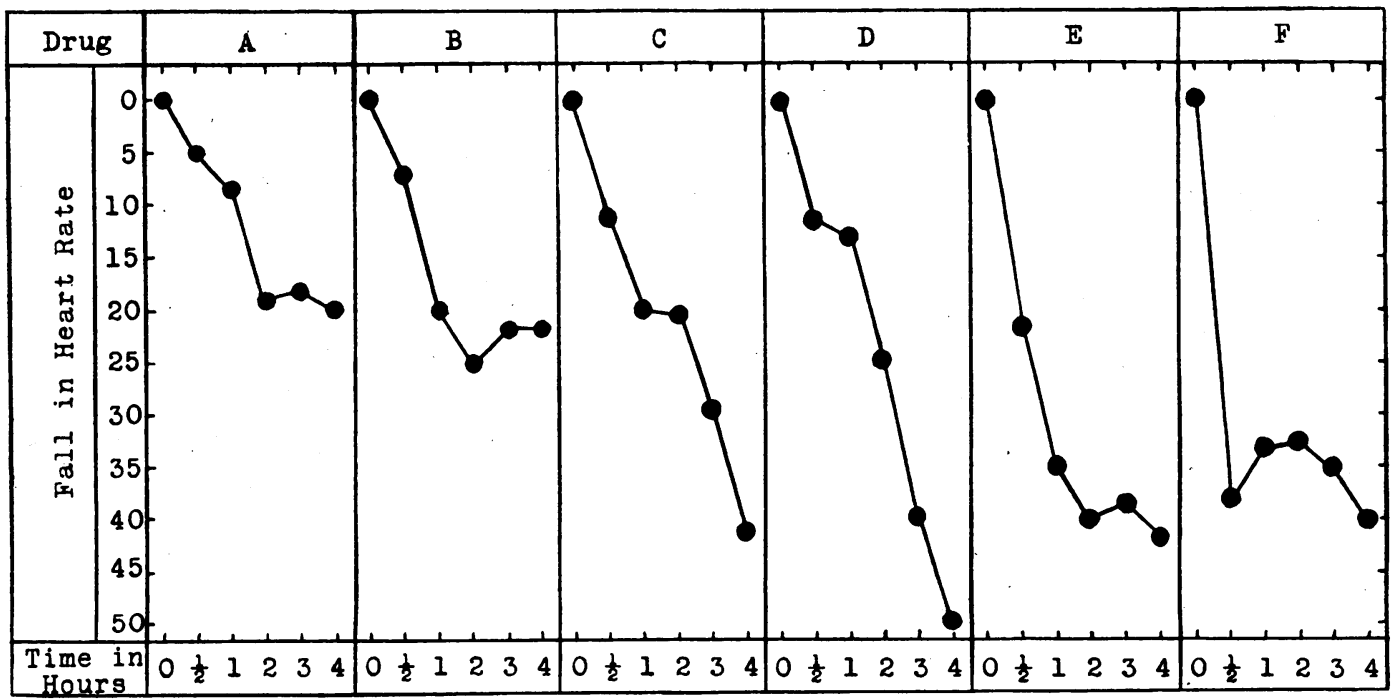

Fig. 11.-Rapid digitalization in a man aged 31 with mitral stenosis and auricular fibrillation. (A) Lanatoside C, $3.0 \mathrm{mg}$. by mouth. (B) K-Strophanthosid, $0.5 \mathrm{mg}$. intravenously. (C) Digitaline (Nativelle), $2.0 \mathrm{mg}$. by mouth. (D) Digoxin, $3.0 \mathrm{mg}$. by mouth. (E) Digitaline (Nativelle), 1.5 mg. intravenously. (F) Lanatoside C, $1.5 \mathrm{mg}$. intravenously. 


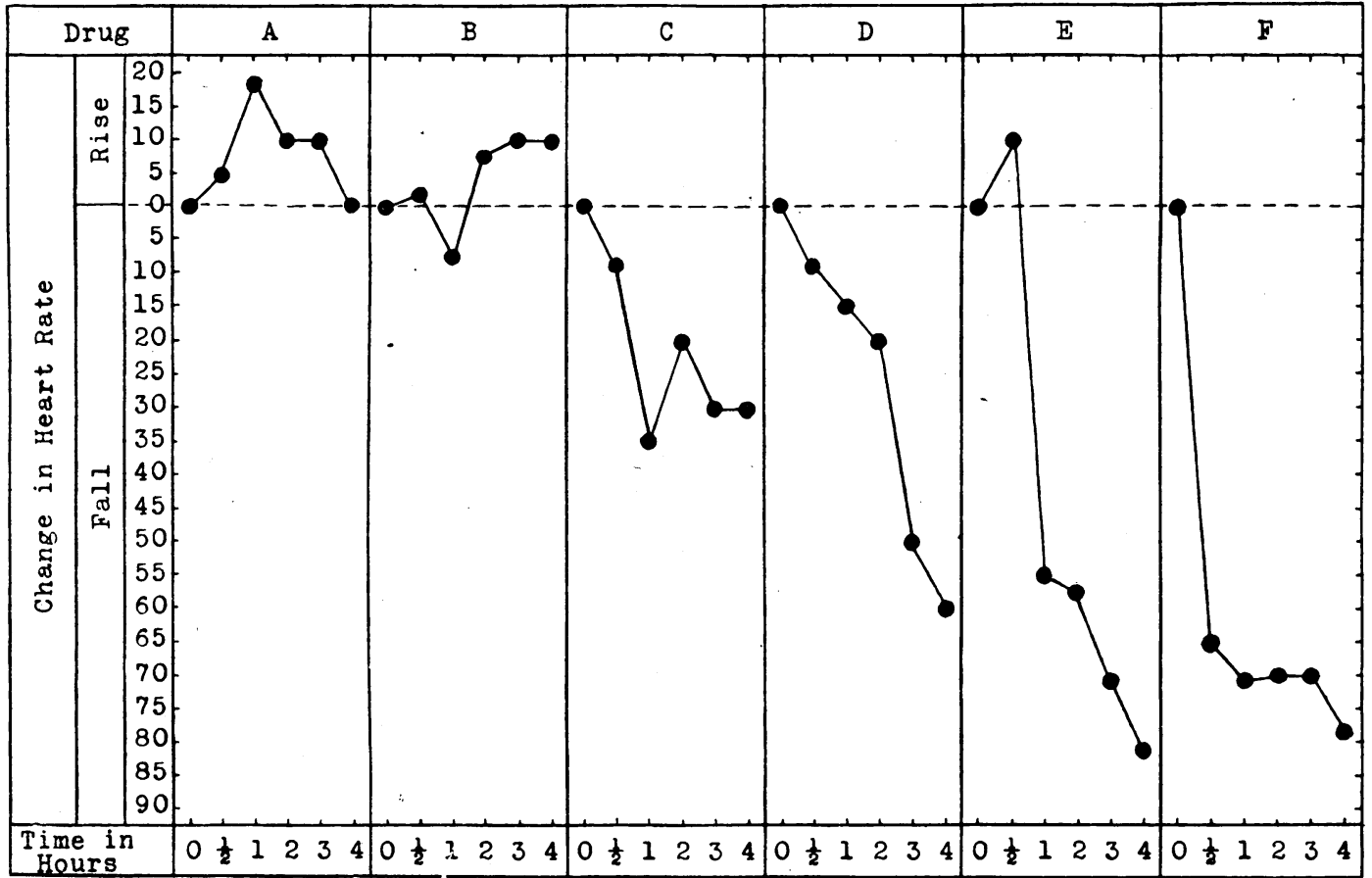

FIG. 12.-Rapid digitalization in a woman aged 34 with mitral stenosis and auricular fibrillation. (A) Lanatoside C, $3.0 \mathrm{mg}$. by mouth. (B) Coramine, $1.7 \mathrm{ml}$. intravenously. (C) Lanatoside C, $0.8 \mathrm{mg}$. intravenously. (D) K-Strophanthosid, $1 \mathrm{ml}$. intravenously. (E) Digoxin, $3.0 \mathrm{mg}$. by mouth. (F) Digoxin $1.5 \mathrm{mg}$. intravenously.

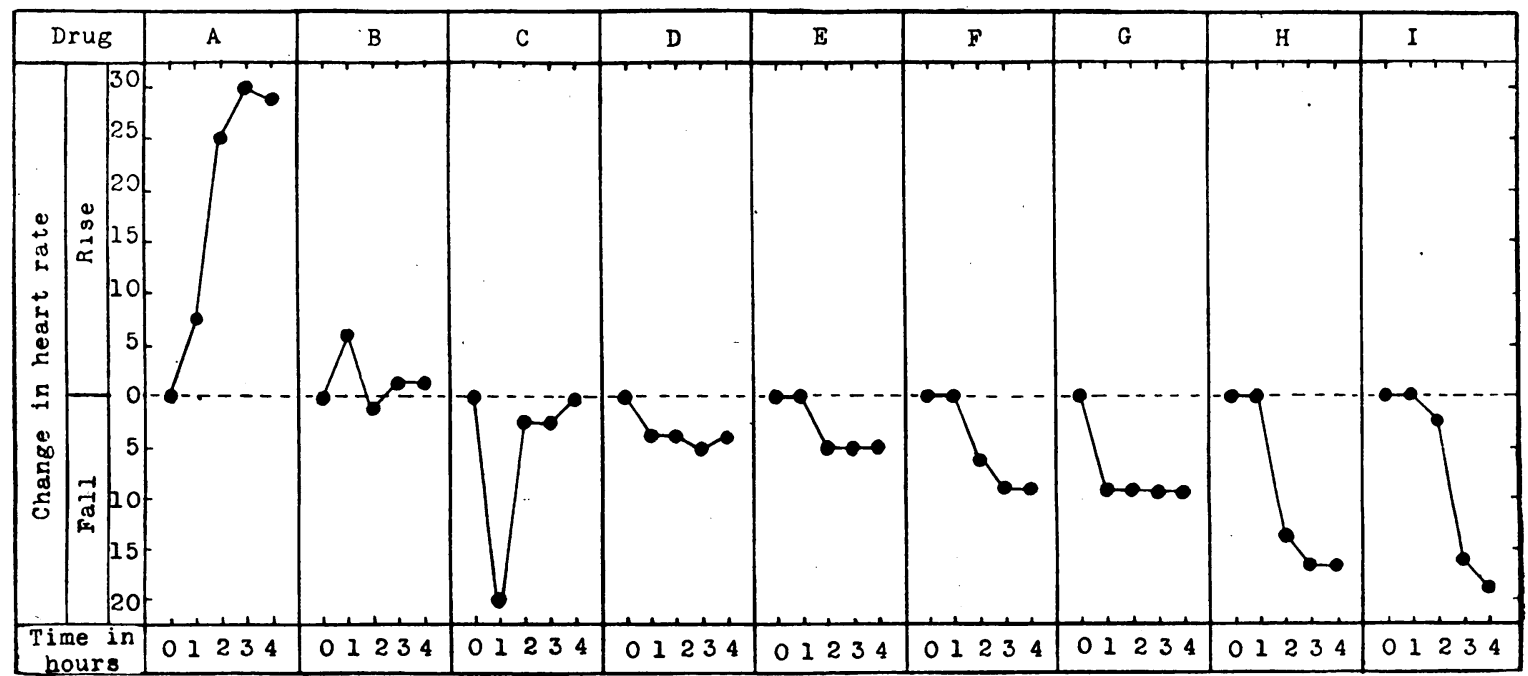

FIG. 13.-Rapid digitalization in a man aged 45 with mitral stenosis and auricular fibrillation. (A) Cardiazol, 2 ml. intravenously. (B) Ouabain, 1/240 gr. intravenously. (C) Strophanthin, 1/100 gr. intravenously. (D) Coramine, $3.4 \mathrm{ml}$. intravenously. (E) Strophanthin, 1/60 gr. intravenously. (F) Digoxin, 1.5 mg. by mouth. (G) Digoxin, $1.0 \mathrm{mg}$. intravenously.

(H) Digoxin $1.5 \mathrm{mg}$. chewed. (I) Digoxin, $3.0 \mathrm{mg}$. by mouth. 


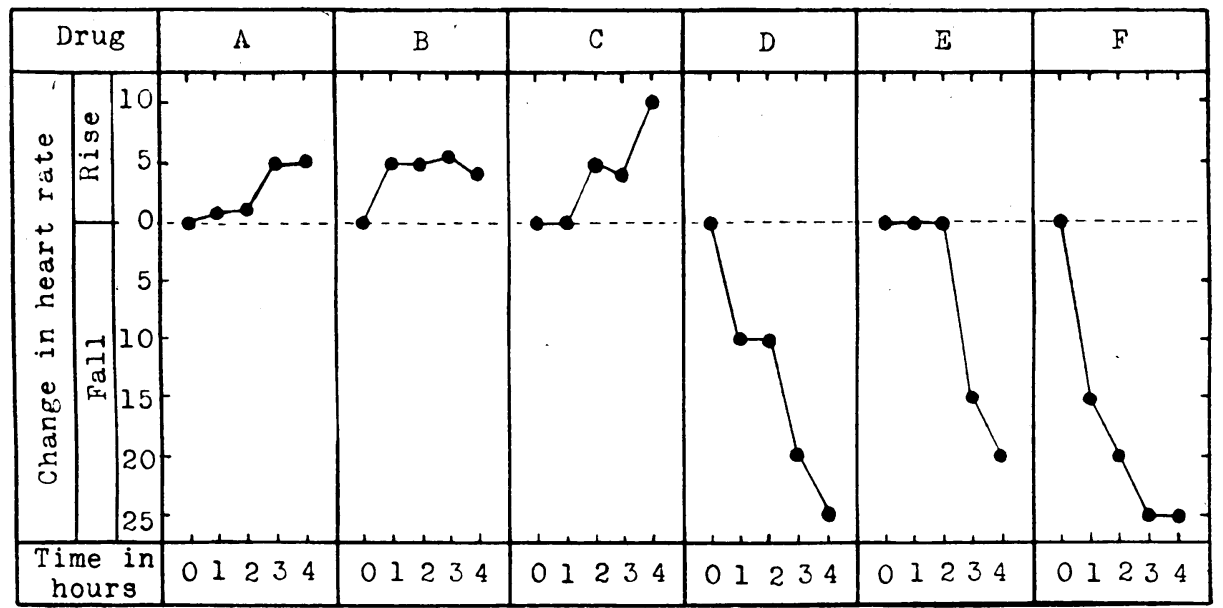

FIG. 14.-Rapid digitalization in a man aged 54 with hypertension and auricular fibrillation. (A) Digitalis leaf, 6 grains by mouth. (B) Tincture of digitalis, 2 drachms by mouth. (C) Digitaline (Allen and Hanbury), 1/30 gr. by mouth. (D) Strophanthin, 1/100 gr. intravenously. (E) Digoxin, $1.5 \mathrm{mg}$. by mouth. (F) Digoxin, $1.0 \mathrm{mg}$. intravenously.

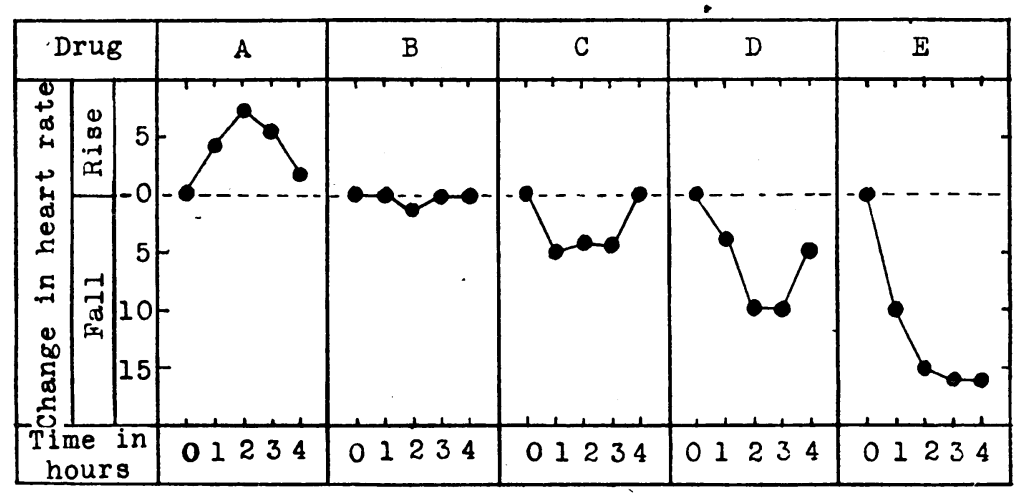

FIG. 15.-Rapid digitalization in a man aged 61 with hypertension and auricular fibrillation. (A) Strophanthin, 1/100 gr. intravenously. (B) Digitaline (Allen and Hanbury), 1/30 gr. by mouth. (C) Digoxin, 1.5 mg. by mouth. (D) Digitalis leaf, 6 gr. by mouth. (E) Digoxin, $1.0 \mathrm{mg}$. intravenously.

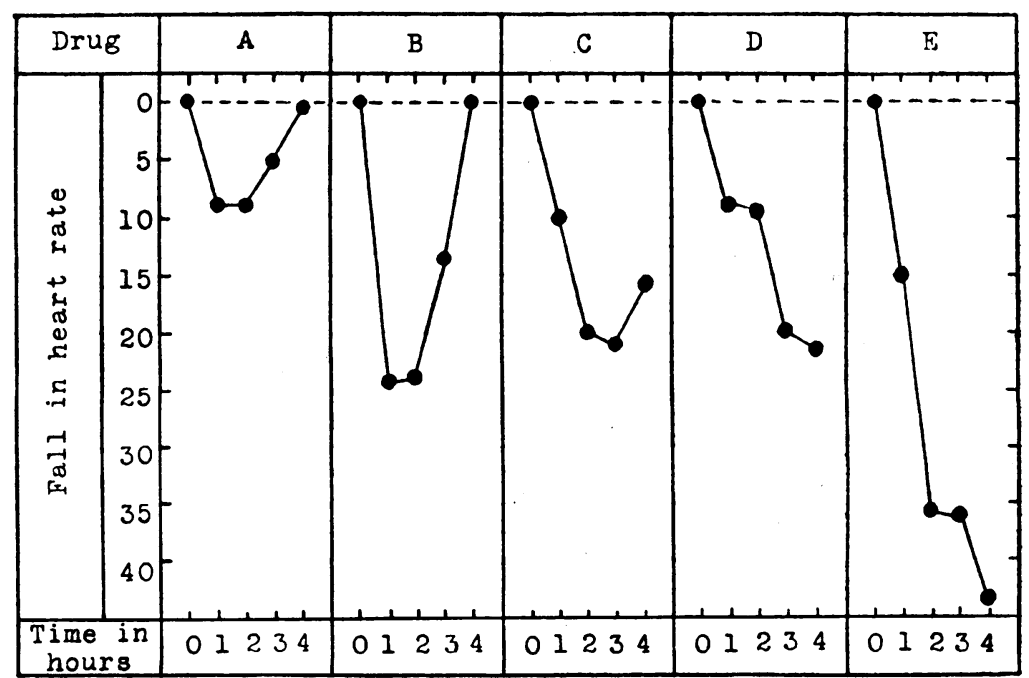

FIG. 16.-Rapid digitalization in a woman aged 31 with mitral stenosis and auricular fibrillation. (A) Digitaline (Nativelle), 1/300 gr. intravenously. (B) Strophanthin, 1/100 gr. intravenously. (C) Digitaline (Nativelle), 1/50 gr. by mouth. (D) Digoxin, $1 / 5 \mathrm{mg}$. by mouth. (E) Digoxin, $1.5 \mathrm{mg}$. intravenously. 


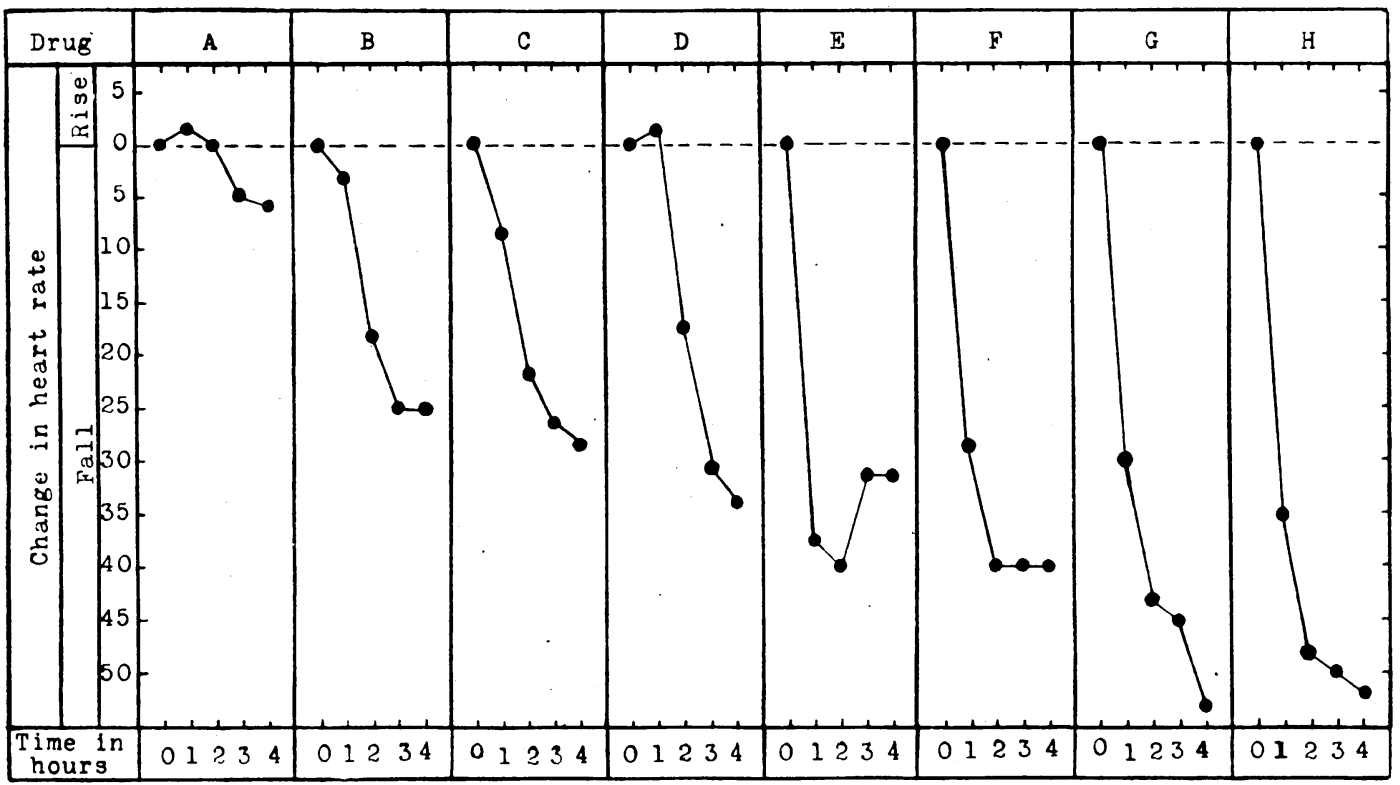

FIG. 17.-Rapid digitalization in a woman with mitral stenosis and auricular fibrillation. (A) Coramine $3.4 \mathrm{ml}$. intravenously. (B) Digoxin, $1.0 \mathrm{mg}$. by mouth. (C) Digoxin, $2.0 \mathrm{mg}$. by mouth. (D) Digoxin, $2.0 \mathrm{mg}$. by mouth. (E) Strophanthin, 1/60 gr. intravenously. (F) Digoxin, 1.0 mg. intravenously. (G) Lanatoside C, $0.8 \mathrm{mg}$. intravenously. (H) K-Strophanthosid, $1 \mathrm{ml}$. intravenously.

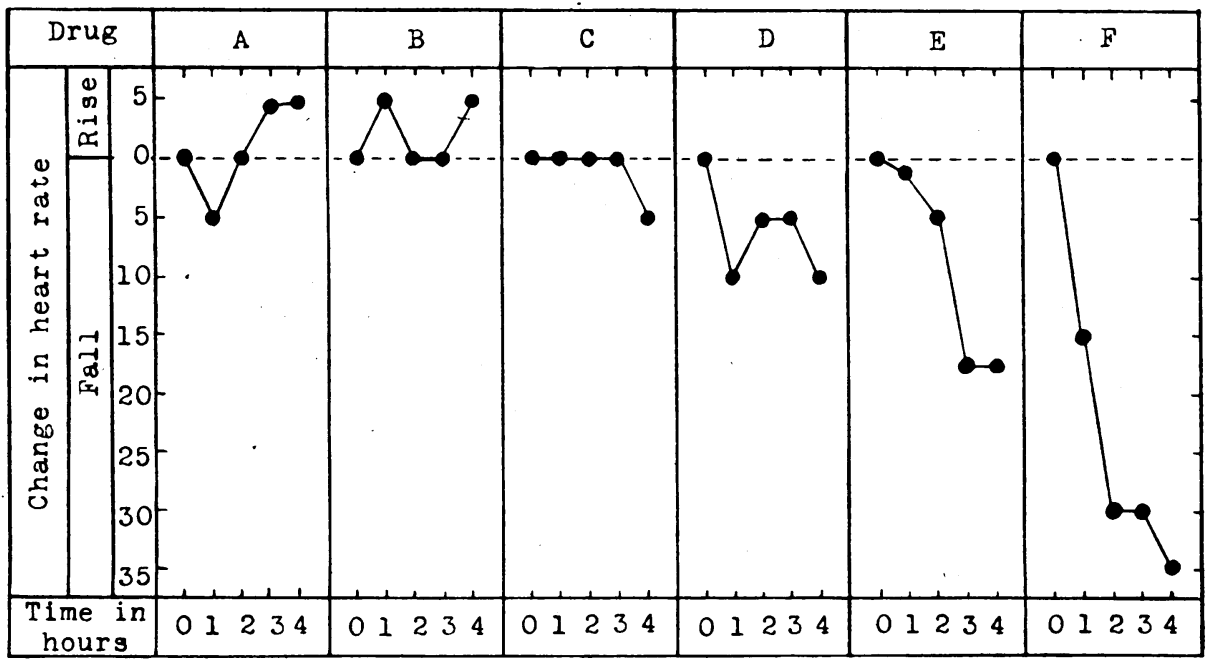

FIG. 18.-Rapid digitalization in a man aged 46 with mitral stenosis and auricular fibrillation. (A) Digitaline (Allen and Hanbury), $1 / 30$ gr. by mouth. (B) Tincture of digitalis, 2 drachms by mouth. (C) Digitalis leaf, 6 gr. by mouth. (D) Strophanthin, 1/100 gr. intravenously. (E) Digoxin, $1.5 \mathrm{mg}$. by mouth. (F) Digoxin, $1.0 \mathrm{mg}$. intravenously. 


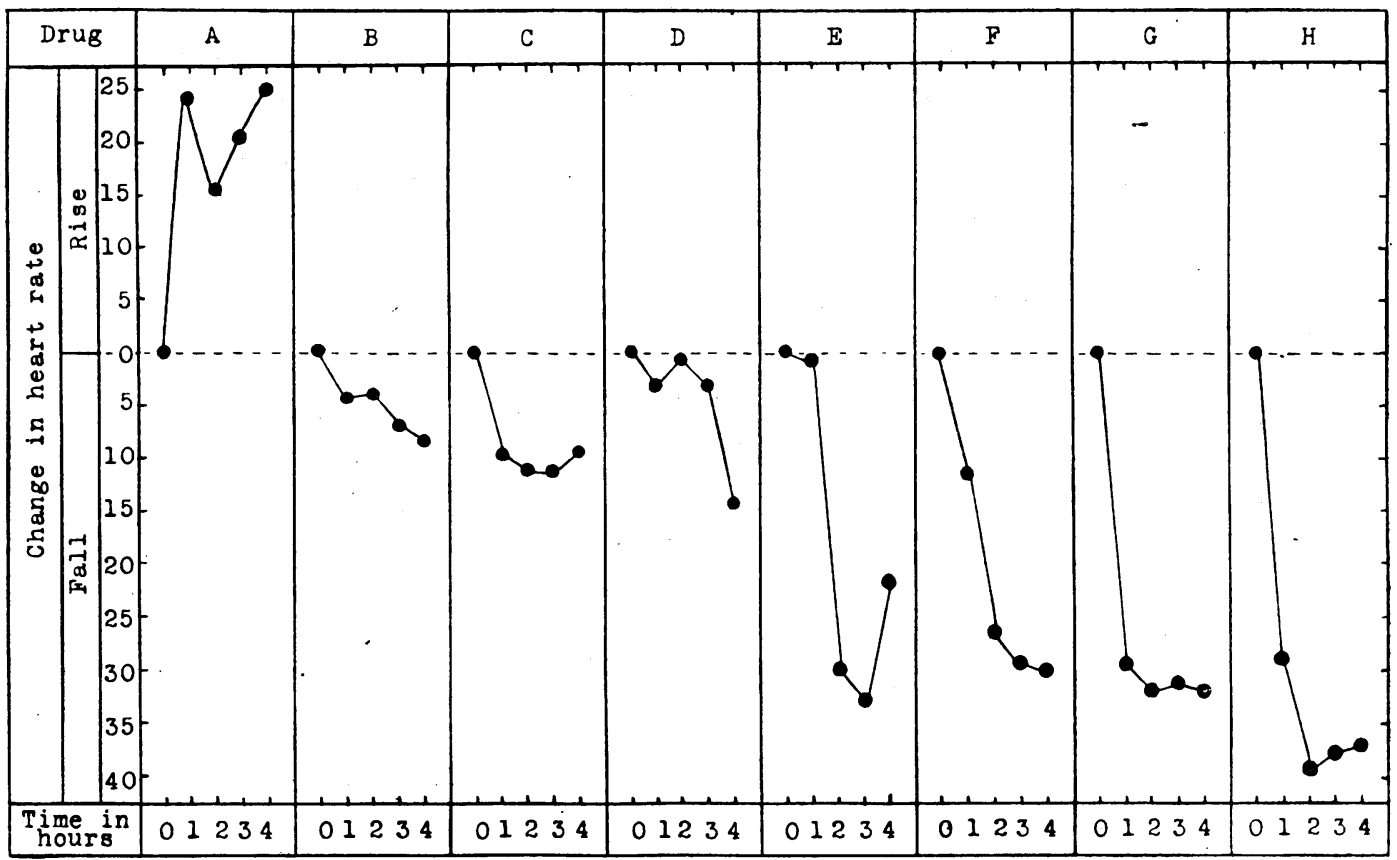

FIG. 19.-Rapid digitalization in a woman aged 76 with mitral stenosis and auricular fibrillation. (A) Cycliton, $2 \mathrm{ml}$. intravenously. (B) Digitaline (Nativelle), $1 / 240 \mathrm{gr}$. intramuscularly. (C) Ouabain, 1/240 gr. intravenously. (D) Digalen, $1 \mathrm{ml}$. intravenously. (E) Digoxin, $1 \mathrm{mg}$. intravenously. (F) Strophanthin, 1/60 gr. intravenously. (G) Lanatoside C, $4 \mathrm{ml}$. intravenously. (H) K-Strophanthosid, $1 \mathrm{ml}$. intravenously.

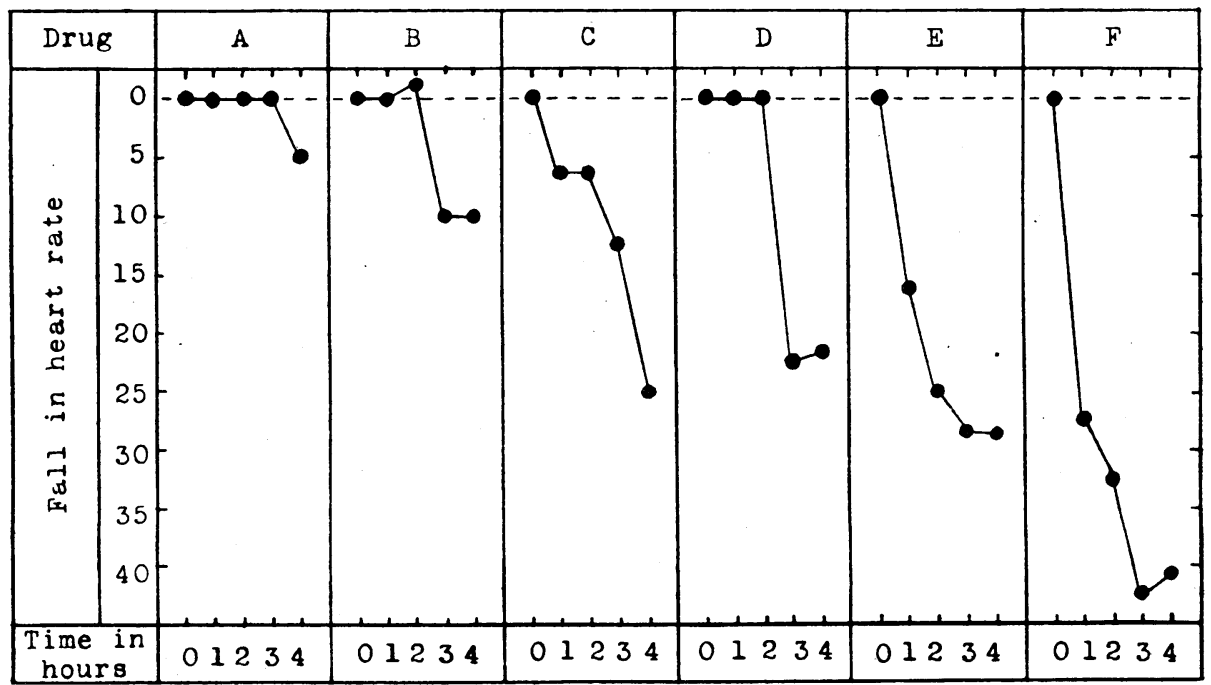

FIG. 20.-Rapid digitalization in a woman aged 36 with mitral stenosis and auricular fibrillation. (A) Strophanthin, 1/100 gr. intravenously. (B) Digoxin, 1.5 mg. by mouth. (C) Digoxin, $1.5 \mathrm{mg}$. chewed. (D) The same as C. (E) Digoxin, $1.5 \mathrm{mg}$. by mouth. (F) Digoxin, $1.0 \mathrm{mg}$. intravenously. 
Ouabain was given intravenously in a dose of $1 / 240$ gr. to two cases. It produced no effect in one case and only a slight effect in another. It was not given a sufficient number of times to justify any comparison with other drugs.

\section{Strophosid}

Strophosid (Sandoz) in a dose of $1 \mathrm{ml}$. containing $0.5 \mathrm{mg}$. of $\mathrm{k}$-strophanthosid, was given 9 times. It produced a good effect in 5, a moderate effect in 2, and a slight effect in 1 case. In one there was a considerable fall during the first two hours, but the heart rate had returned almost to its previous level by the fourth hour. In the absence of any previous reports of the drug, the dosage of $1 \mathrm{ml}$. recommended by the manufacturers was regarded as a full dose. It was compared with strophanthin intravenously 3 times, with ouabain once, with digoxin by mouth 8 times, with digoxin intravenously 5 times, with digitaline (Nativelle) by mouth 4 times, with digitaline (Nativelle) intravenously 3 times, and with lanatoside $\mathrm{C}$ intravenously 7 times. The results are summarized in Table II.

\section{Digitalis tincture and leaf}

The tincture was given by mouth 3 times in a dose of 2 drachms. It had practically no effect in 2 cases, and only a slight effect in one within four hours. Digitalis leaf by mouth in a dose of 6 grains was given 3 times. In one case its administration was followed by a slight rise in heart rate, in one by a slight fall and in the third there was no change. As the full comparable dose of digitalis leaf lies between 15 and 25 grains these results could not be compared with other preparations.

Digalen, a water soluble preparation of total digitalis alkaloids, was given twice intravenously in a dose of $1 \mathrm{ml}$. It produced a good effect in one case, and a moderate effect in the other. It was not given a sufficient number of times to allow comparison with other drugs.

Digitaline (Allen and Hanbury) was given three times by mouth in a dose of $1 / 30 \mathrm{gr}$. ( $2 \cdot 2 \mathrm{mg}$.). In no case did a significant fall in the heart rate occur within four hours.

TABLE II

The Effect of Strophosid Intravenously Compared with that of Other Preparations

\begin{tabular}{|c|c|c|c|c|c|c|c|c|c|}
\hline \multirow{3}{*}{\multicolumn{2}{|c|}{ Drug for comparison }} & & \multirow{3}{*}{$\begin{array}{l}\text { No. of } \\
\text { trials }\end{array}$} & \multicolumn{6}{|c|}{$\begin{array}{c}\text { Efficiency of Strophosid intravenously compared with that of } \\
\text { other preparations }\end{array}$} \\
\hline & & & & \multicolumn{3}{|c|}{ Within 2 hours } & \multicolumn{3}{|c|}{ Within 4 hours } \\
\hline & & & & Greater & Equal & Less & Greater & Equal & Less \\
\hline $\begin{array}{l}\text { Strophanthin } \\
\text { Ouabain .. } \\
\text { Digalen .. } \\
\text { Digitaline (Native } \\
\text { Digitaline (Native } \\
\text { Digoxin (m) } \\
\text { Digoxin (v) } \\
\text { Lanatoside C (v) }\end{array}$ & $\begin{array}{l}\cdots \\
\cdots \\
\cdots \\
(\mathrm{m}) \\
\ldots \\
\ldots \\
\ldots\end{array}$ & $\begin{array}{l}\ldots \\
\cdots \\
\cdots \\
\ldots \\
\cdots \\
\cdots \\
\cdots\end{array}$ & $\begin{array}{l}3 \\
1 \\
2 \\
4 \\
3 \\
8 \\
5 \\
7\end{array}$ & $\begin{array}{l}2 \\
1 \\
1 \\
2 \\
4 \\
4 \\
3\end{array}$ & $\frac{\frac{1}{2}}{\frac{2}{1}}$ & $\begin{array}{l}- \\
\overline{1} \\
\overline{3} \\
3 \\
2 \\
3\end{array}$ & $\begin{array}{l}2 \\
1 \\
1 \\
1 \\
2 \\
3 \\
3\end{array}$ & $\begin{array}{l}\frac{1}{-} \\
\frac{1}{1} \\
\frac{1}{1}\end{array}$ & $\begin{array}{l}- \\
1 \\
3 \\
3 \\
5 \\
2 \\
3\end{array}$ \\
\hline
\end{tabular}

TABLE III

The Effect of Digitaline (Nativelle) by Mouth Compared with that of Other Preparations

\begin{tabular}{|c|c|c|c|c|c|c|c|c|}
\hline \multirow{3}{*}{ Drug for comparison } & & \multirow{3}{*}{$\begin{array}{l}\text { No. of } \\
\text { trials }\end{array}$} & \multicolumn{6}{|c|}{$\begin{array}{l}\text { Efficiency of digitaline (Nativelle) by mouth compared with that } \\
\text { of other preparations }\end{array}$} \\
\hline & & & \multicolumn{3}{|c|}{ Within 2 hours } & \multicolumn{3}{|c|}{ Within 4 hours } \\
\hline & & & Greater & Equal & Less & Greater & Equal & Less \\
\hline 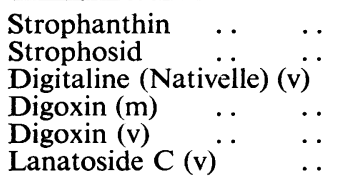 & \begin{tabular}{l|}
$\cdots$ \\
$\cdots$ \\
$\cdots$ \\
$\cdots$ \\
$\cdots$
\end{tabular} & $\begin{array}{l}1 \\
4 \\
4 \\
5 \\
3 \\
5\end{array}$ & $\begin{array}{c}- \\
\overline{3} \\
1 \\
-\end{array}$ & $\begin{array}{l}\overline{2} \\
1 \\
1 \\
-1\end{array}$ & $\begin{array}{l}1 \\
2 \\
3 \\
1 \\
2 \\
4\end{array}$ & $\begin{array}{l}1 \\
3 \\
1 \\
1 \\
1 \\
-\end{array}$ & $\frac{-}{1}$ & $\begin{array}{l}-1 \\
2 \\
4 \\
2 \\
4\end{array}$ \\
\hline
\end{tabular}


TABLE IV

The Effect of Digitaline (Nativelle) Intravenously Compared with that of Other Preparations

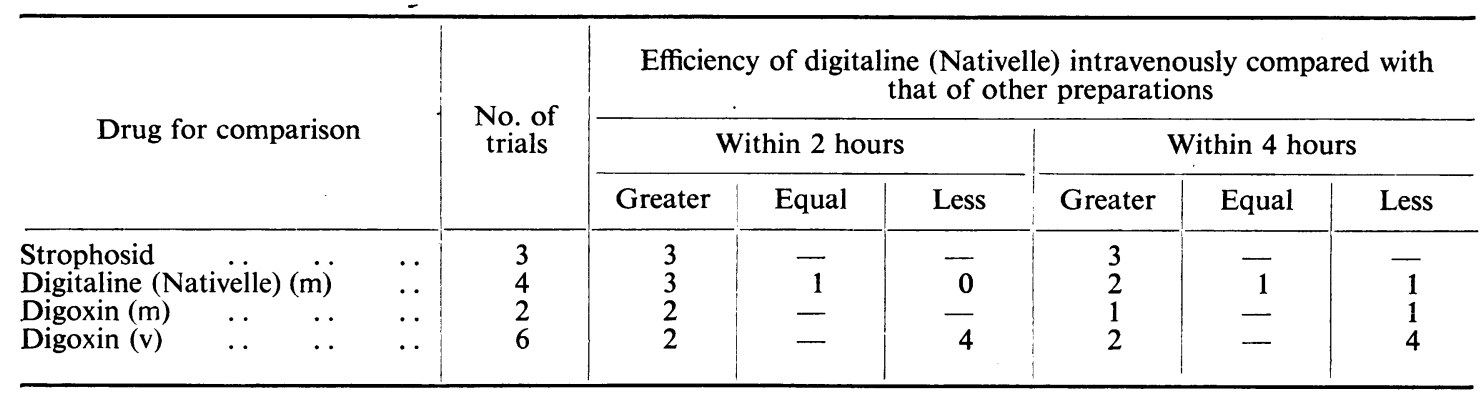

\section{Digitaline (Nativelle)}

This preparation was given by mouth 8 times; once as $1.25 \mathrm{mg}$. with slight effect, once as $1.3 \mathrm{mg}$. with moderate effect, once as $1.5 \mathrm{mg}$. with good effect, once as $1.75 \mathrm{mg}$. with good effect, and four times as $2 \mathrm{mg}$.; with this dosage it had a good effect twice, moderate once, while on one occasion there was no fall in the heart rate. The full dose by mouth is generally accepted as $1.2 \mathrm{mg}$. and this was taken as the minimum for purposes of comparison. It was compared with strophanthin intravenously 4 times, with digoxin by mouth 5 times, with digoxin intravenously 3 times, and with lanatoside C intravenously 5 times (see Table III). It was given intramuscularly in a dose of $0.27 \mathrm{mg}$. in one case when a slight fall in heart rate occurred.

It was given 7 times intravenously. Once in a dose of $0 \cdot 22 \mathrm{mg}$. it produced a sustained fall in heart rate; three times in a dose of $1.2 \mathrm{mg}$. it had a good effect and 3 times as $1.5 \mathrm{mg}$. it also had a good effect. The full intravenous dose is generally accepted as $1.2 \mathrm{mg}$. It was compared with strophosid intravenously three times, with digitaline (Nativelle) by mouth four times, with digoxin by mouth twice, and with lanatoside $\mathrm{C}$ intravenously six times. The results are shown in Table IV.

\section{Digoxin}

The relationship of the oral to the intravenous dose of digoxin, and the size of the full therapeutic dose was studied in 11 cases, because this did not appear to be known and because the full doses which have been generally recommended appeared to be inadequate. The effectiveness of digoxin when chewed was studied on three occasions. In one case, $1.5 \mathrm{mg}$. was chewed with the same effect on two occasions. The same dose was swallowed twice by this patient, producing once a slightly better effect than when it was chewed, and on the other a much lesser effect. In another case, $1.5 \mathrm{mg}$. was chewed on one occasion and swallowed on another. It pro- duced a better effect when chewed, but the actual fall in heart rate was not great and the difference in effect of the two methods of administration was slight.

In two cases an equal dose was given intravenously and orally. In each a very much better effect was obtained with the intravenous dose. In one case an oral dose one-third times larger than the intravenous dose was given; the intravenous dose was slightly more effective. On seven occasions the oral dose was one-half times larger than the intravenous dose and each time the intravenous

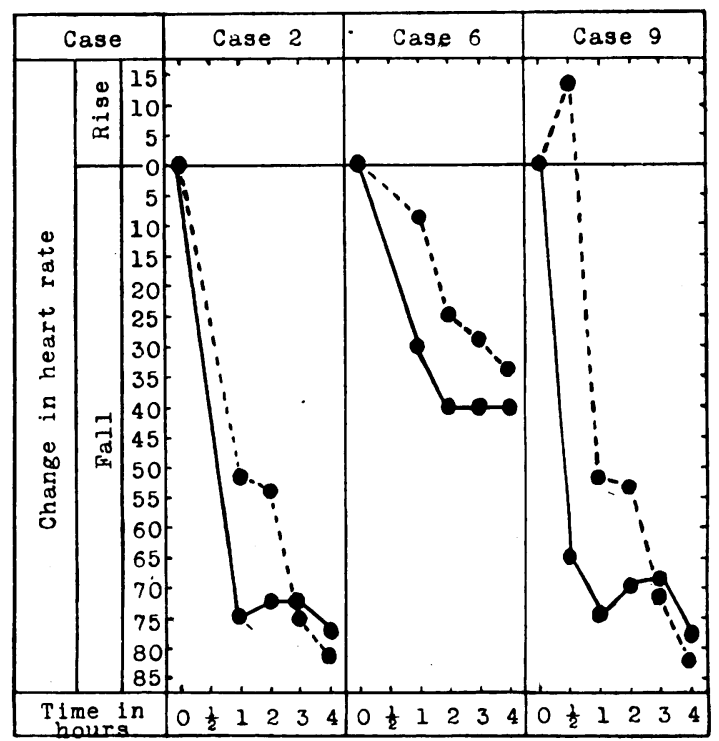

FIG. 21.-A comparison of the effects of digoxin given by mouth and half the amount given intravenously in three cases. In Case 2 digoxin, $3.0 \mathrm{mg}$. was given by mouth (represented by discontinuous lines) and $1.5 \mathrm{mg}$. intravenously (continuous lines). In Case 6 digoxin, $2.0 \mathrm{mg}$. was given by mouth and $1.0 \mathrm{mg}$. intravenously. In Case 9 digoxin, $3.0 \mathrm{mg}$. was given by mouth and $1.5 \mathrm{mg}$. intravenously. 
dose produced a better effect, usually much better. In two cases the oral dose was twice the intravenous dose, and an equal effect was obtained. In a third case an oral dose twice the intravenous dose was given on two occasions; the intravenous dose was slightly more effective (Fig. 21). Although occasionally the effect of digoxin by mouth was not complete within four hours, any further effect was very slight.

Digoxin was given by mouth 18 times. It was given as $1.0 \mathrm{mg}$. once with good effect, as $1.25 \mathrm{mg}$. once with moderate effect, as $1.5 \mathrm{mg}$. eight times, as $2.0 \mathrm{mg}$. four times, and as $3.0 \mathrm{mg}$. four times. In the 8 cases that received $1.5 \mathrm{mg}$. a good effect was seen three times, a moderate effect four times, and no effect once. With a dose of $2.0 \mathrm{mg}$. a good effect was seen three times, and there was no fall in the heart rate in one case. With a dose of $3.0 \mathrm{mg}$. a good effect was seen in all four cases. The minimal full dose was regarded as $1.25 \mathrm{mg}$. for the purpose of comparison. It was compared with strophanthin intravenously 14 times, with ouabain intravenously twice, with strophosid intravenously 8 times, with digalen intravenously twice, with digitaline (Nativelle) by mouth 5 times, with digitaline (Nativelle) intravenously twice, with digoxin intravenously 14 times, and with lanatoside $C$ intravenously 7 times. The results are shown in Table $\mathrm{V}$.

Digoxin was given intravenously 14 times. It was given as $1.0 \mathrm{mg} .8$ times, producing a good effect in seven and a moderate effect in one, as $1.25 \mathrm{mg}$. twice, producing a good effect once, and an ectopic rhythm in the other, as $1.5 \mathrm{mg}$. 4 times producing a good effect 3 times and a moderate effect once. The minimum full dose intravenously was regarded as $1.0 \mathrm{mg}$. It was compared with strophanthin intravenously ten times, with ouabain intravenously twice, with strophosid intravenously five times, with digalen twice, with digitaline (Nativelle) by mouth three times, with digitaline (Nativelle) intravenously four times, with digoxin by mouth fourteen times, and with lanatoside $\mathrm{C}$ intravenously eight times. The results are shown in Table VI.

TABLE V

The Effect of Digoxin by Mouth Compared with that of Other Preparations

\begin{tabular}{ll|r|r|r|r|r|r|r}
\hline & & & & \multicolumn{3}{|c|}{ Efficiency of digoxin by mouth compared with that of other } \\
preparations
\end{tabular}

TABLE VI

The Effect of Digoxin Intravenously Compared with that of Other Preparations

\begin{tabular}{|c|c|c|c|c|c|c|c|c|c|c|}
\hline \multirow{3}{*}{\multicolumn{3}{|c|}{ Drug for comparison }} & & \multirow{3}{*}{$\begin{array}{l}\text { No. of } \\
\text { trials }\end{array}$} & \multicolumn{6}{|c|}{$\begin{array}{c}\text { Efficiency of digoxin intravenously compared with that of other } \\
\text { preparations }\end{array}$} \\
\hline & & & & & \multicolumn{3}{|c|}{ Within 2 hours } & \multicolumn{3}{|c|}{ Within 4 hours } \\
\hline & & & & & Greater & Equal & Less & Greater & Equal & Less \\
\hline $\begin{array}{l}\text { Strophanthin } \\
\text { Ouabain } \\
\text { Strophosid } \\
\text { Digalen . } \\
\text { Digitaline (Na } \\
\text { Digitaline (Na } \\
\text { Digoxin (m) } \\
\text { Lanatoside C }\end{array}$ & $\begin{array}{l}\ldots \\
\ldots \\
\ldots \\
\text { ivell } \\
\text { ivell } \\
\ldots \\
\text { v) }\end{array}$ & $\begin{array}{l}\ldots \\
\ldots \\
\ldots \\
\ddot{(m)} \\
(\mathrm{v}) \\
\ldots \\
\ldots\end{array}$ & $\begin{array}{l}\ldots \\
\ldots \\
\ldots \\
\ldots \\
\cdots \\
\ldots\end{array}$ & $\begin{array}{r}10 \\
2 \\
5 \\
2 \\
3 \\
4 \\
14 \\
8\end{array}$ & $\begin{array}{r}8 \\
2 \\
2 \\
2 \\
2 \\
2 \\
14 \\
2\end{array}$ & $\begin{array}{l}1 \\
= \\
- \\
- \\
-\end{array}$ & $\begin{array}{l}\frac{1}{3} \\
\frac{1}{2} \\
\frac{5}{5}\end{array}$ & $\begin{array}{l}9 \\
2 \\
2 \\
1 \\
2 \\
2 \\
8 \\
2\end{array}$ & $\begin{array}{l}\frac{1}{-} \\
\frac{1}{1} \\
-\end{array}$ & $\begin{array}{l}- \\
\frac{3}{3} \\
1 \\
1 \\
3 \\
6\end{array}$ \\
\hline
\end{tabular}




\section{Lanatoside $C$}

Lanatoside $\mathrm{C}$ was given by mouth 5 times. Once in a dose of $1.0 \mathrm{mg}$. there was a temporary fall in the heart rate, which, however, rose almost to its previous level within four hours. It was given four times as $3.0 \mathrm{mg}$. In one case a fall in heart rate did not occur, in another there was a slight fall, while in a third a moderate fall took place. In the last three there was an initial fall in rate, but it returned to the previous level within three hours. As the full dose of lanatoside $\mathrm{C}$ is probably about $10 \mathrm{mg}$. by mouth, for its rate of absorption is variable, its effect could not be compared with that of other preparations.

Lanatoside $\mathrm{C}$ was given intravenously 11 times. In a dose of $0.8 \mathrm{mg}$. it had a good effect in two cases, and moderate in one. As $1.0 \mathrm{mg}$. it was given once producing a moderate effect, and as $1.2 \mathrm{mg}$. snce producing a good effect. It was given 6 times as $1.5 \mathrm{mg}$. with a good effect in all cases. For purposes of comparison $0.8 \mathrm{mg}$. intravenously was regarded as a full dose. It was compared with strophanthin intravenously three times, with ouabain intravenously once, with strophosid intravenously seven times, with digalen intravenously twice, with digitaline (Nativelle) intravenously six times, with digitaline (Nativelle) by mouth five times, with digoxin by mouth seven times, and with digoxin intravenously eight times. The results are shown in Table VII. nine, and digitaline (Nativelle) intravenously once out of six. Intravenous digoxin was given 14 times and a very rapid effect was seen 8 times. With lanatoside $C$ intravenously a very rapid effect occurred in 7 out of 10 trials.

Toxic effects. Several cases experienced slight nausea after some preparations, but in only three cases did vomiting occur: Paroxysmal tachycardia occurred in one patient $1 \frac{1}{2}$ hours after receiving $1.25 \mathrm{mg}$. of digoxin intravenously ; it lasted for 10 hours and was not accompanied by any distress.

\section{Discussion}

In earlier times ideas on the dosage of digitalis became confused, and its value to some extent suffered on this account. Generally it was used in inadequate doses, and in the absence of any method of standardizing the strength of such a potent drug it is not surprising that physicians tended to err on the side of under-dosage. Many workers have pointed out the variations in potency of preparations assayed by animal experiments and the differences in effect, when applied to man, of preparations having the same potency by animal assay (Cushny, 1925; Gold et al., $1941 a, b$; Gold and Cattell, 1941 ; Lyon and Gilchrist, 1927), but the introduction of such pharmacological assay has nevertheless been a great advance in the use of digitalis.

Mackenzie (1914) advised "steadily to push the

TABLE VII

The Effect of Lanatoside C Intravenously Compared with that of Other Preparations

\begin{tabular}{|c|c|c|c|c|c|c|c|c|c|c|}
\hline \multirow{3}{*}{\multicolumn{4}{|c|}{ Drug for comparison }} & \multirow{3}{*}{$\begin{array}{c}\text { No. of } \\
\text { trials } \\
\text { ? }\end{array}$} & \multicolumn{6}{|c|}{$\begin{array}{l}\text { Efficiency of lanatoside C.intravenously compared with that of } \\
\text { other preparations }\end{array}$} \\
\hline & & & & & \multicolumn{3}{|c|}{ Within 2 hours } & \multicolumn{3}{|c|}{ Within 4 hours } \\
\hline & & & & & Greater & Equai & Less & Greater & Equal & Less \\
\hline Strophanthin & .. & .. & .. & 3 & 2 & 1 & - & 2 & - & 1 \\
\hline Ouabain $\ldots$ & .. & .. & .. & 1 & 1 & - & $\overline{0}$ & 1 & - & -2 \\
\hline $\begin{array}{l}\text { Strophosid } \\
\text { Digalen }\end{array}$ & .. & .. & . & 7 & 3 & 1 & 3 & 3 & 1 & 3 \\
\hline $\begin{array}{l}\text { Digalen } \\
\text { Digitaline } \\
\text { Nat }\end{array}$ & ivell & & $\cdots$ & $\begin{array}{l}2 \\
5\end{array}$ & $\begin{array}{l}1 \\
4\end{array}$ & $\overline{1}$ & 1 & $\begin{array}{l}1 \\
4\end{array}$ & $\overline{1}$ & 1 \\
\hline $\begin{array}{l}\text { Digitaline (Nat } \\
\text { Digitaline (Nat }\end{array}$ & ivell & & 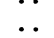 & 6 & 4 & - & 2 & 4 & - & 2 \\
\hline Digoxin (m) & .. & & .. & 7 & 4 & - & 3 & 4 & - & 3 \\
\hline Digoxin (v) & .. & 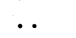 & .. & 8 & 5 & 1 & 2 & 6 & - & 2 \\
\hline
\end{tabular}

Very rapid digitalis action. Full digitalis effects within one hour were only seen with intravenous administration. A fall occasionally occurred within 15 to 30 minutes. Strophanthin produced such a rapid effect once in a dose of $1 / 60$ gr., out of a total of nine intravenous administrations. Strophosid produced a very rapid effect three times out of drug, whichever preparation is employed, until a reaction is observed." He then omitted the drug for a few days, starting again on half the dosage until further adjustment became necessary. He advocated instructing the patient in the symptoms of overdosage, and found that most patients by their own sensations quickly acquired the knowledge of how 
much of the drug was needed. Mackenzie recorded an interesting example of the intelligent use of the drug by a patient who came under his care and who made his own infusion of foxglove and was in the habit of taking the drug whenever he was unable to lace up his boots. He mainly employed the tincture, giving one drachm daily, in doses of 15 to 20 minims, in cases of marked failure until a reaction was observed, but in cases of great distress and urgency he used 2 drachms daily when the effect was usually seen in two to three days. He stressed that its dosage must be determined individually "for each patient.

Cushny (1925) wrote that the best results are obtained only by the largest doses which can be given without gastric or intestinal symptoms, and this principle with certain modifications has been reiterated by nearly all writers on the subject since. A study of methods of rapid digitalization began with Eggleston's (1915) work on the dosage of digitalis. He found that the average dose of the tincture necessary to produce an ideal therapeutic effect was 0.146 cat units per $\mathrm{lb}$. weight, i.e. about 22 cat units for a patient of $150 \mathrm{lb}$. ; this is roughly equivalent to 33 grains of digitalis leaf. White and Morris (1918) tried the method and reported favourably on it. Fraser (1922) employed it in 14 cases using slightly smaller doses and concluded that it was very useful in suitable cases. The amount calculated by Eggleston was that necessary to produce a full therapeutic effect just short of toxic doses, and in fact in many cases it did produce toxic effects. That this dose is greater than that necessary to produce a therapeutic effect has been pointed out by many workers. Marvin (1928) stated that his custom in rapid digitalization was to calculate the amount according to Eggleston's formula, and then to give a little less than the total amount. Robinson, White, Eggleston, and Hatcher (1924) and Levy and Mackie (1927) found that 22 grains (1.5 g.) of digitalis leaf was the average dose necessary to produce full therapeutic effect within forty-eight hours in an adult. It came to be accepted that the dose of digitalis that would produce the optimum effect was less than that necessary to produce any toxic effect in the great majority of cases, that there was in fact a wider therapeutic range to the drug, and that "full dose" digitalization in accordance with Eggleston's original studies was undesirable. Luten (1937) felt that the ideal plan was to ascertain the optimum level of dosage for each individual patient.

The divided dose method of Eggleston; used by the above workers, allows of alteration in the succeeding doses, if indicated by the patient's irregular response to the drug, although the total amount likely to be required was calculated in advance. Attempts to give the whole dose at once have been looked on with disfavour for many reasons. Individual susceptibility to digitalis has sometimes resulted in toxic reaction to an average dose. The inconstant response to doses calculated in accordance with the body weight has been pointed out by Lyon and Gilchrist (1927), while Gold and Travell (1941) found that the body weight was only one factor determining the amount of digitalis necessary for individual patients. The relative inconstancy of preparations assayed by biological methods was a further drawback to their use for massive-dose digitalization. A method of assaying digitalis in man has been produced to overcome the variable effects from preparations assayed in cats (Gold et al., 1942), but it is unlikely to be generally applied. This difficulty, however, is removed by the use of the purified glucosides, in which the dosage by weight has been determined directly in man. Further, the liability of large doses of digitalis tincture and leaf to produce vomiting from its local effect, apart from the central vomiting occurring later when the patient is saturated with the drug, does not apply to the same extent in the case of certain purified glucosides. The absorption of digitalis, although apparently only about 20 per cent, is fairly constant (Eggleston and Wyckoff, 1922 ; Wyckoff and Goldring, 1927), and this favours its use in large doses. The most important objection to the production of full digitalis effects by one dose would appear to lie in the individual variability of the amount required, but since there is a therapeutic range of digitalis dosage, within which the optimum lies, it is unnecessary to give doses just short of producing toxic effects. Gold and De Graff (1930) emphasized the wide margin of safety between the minimal therapeutic and the toxic doses. They also said that in the average ambulatory cases with auricular fibrillation and some heart failure, much less digitalis was required to produce a full effect than was necessary with more severe heart failure, and that in the former cases there was a wide margin of safety between therapeutic and toxic doses; this margin, however, diminished as the failure became more severe: They also pointed out that the effective concentration within the body necessary to maintain full effects was less than that required to initiate them.

In spite of the opinions against one-dose methods, the experience of many workers indicates that under certain conditions the method is safe and in our view it is desirable. Robinson (1920) tried the effect of a single large dose of digitalis, and gave 15 to $25 \mathrm{ml}$. of the tincture of digitalis to 26 patients without producing toxic effects; he concluded that the method was safe under controlled conditions. In 
a series of studies of digitalis medication, Gold and his co-workers (1942 and 1944) have had a wide experience of single dose method of digitalization in which digitalis sufficient to saturate the patient is administered. Digitaline, in view of its constant potency and the fact that in their opinion it is almost completely absorbed, was mostly used and in 1944 they summarized their results, having given this preparation to more than a thousand patients. They found that 1.20 or $1.25 \mathrm{mg}$. (equivalent to 3 cat units) by mouth, produced full digitalization in the average patient, and that minor toxic symptoms such as nausea and vomiting occurred in less than 5 per cent; the effect was complete in four to ten hours. When using an amount of digitalis leaf necessary to produce an equivalent result, which they found to be from 12 to 20 cat units, vomiting occurred in 20 per cent of cases. They stated that digitaline by this method was safe and effective. Maintenance dosage could be started on the following day and adjusted as necessary, or in cases where a full effect had not been produced within twenty-four hours, a larger dose than would normally be required for maintenance could be given on the second day. Katz and Wise (1945) confirmed the safety and efficiency of Gold's method, but stated that they preferred the divided dose technique.

The water-soluble preparations of digitalis leaf for intravenous use vary in their potency and this has lessened their value (Haag and Hatcher, 1929 ; Levy, Bruenn, and Ellis, 1932). Strophanthin intravenously, introduced by Fraenkel and Schwarz (1907), became popular and has remained so on the continent and in Latin America until the present time. Indeed, the question of the value of intravenous therapy in the past has been partly concerned with the relative value of strophanthin as a cardiac remedy. Owing to the development of the Eggleston method of rapid digitalization in this country and America, intravenous digitalis therapy was not common practice until the purified digitalis glucosides came into use in recent years. Mackenzie (1914) stated that intravenous strophanthin may be given in doses of $1 / 250 \mathrm{gr}$., but considered that it was needed only in exceptional and urgent cases, for he had rarely failed to get a reaction in good time by giving digitalis by mouth. The main advantage of intravenous digitalis therapy lies with its rapidity of action. A digitalis effect may be seen within a few minutes. The presence of gastrointestinal upset is a further indication for its use (Wenckebach, 1910), and rectal administration is a poor alternative.

Precision in dosage has been advanced as an argument in its favour (Fraenkel, 1935), because the uncertainty of intestinal absorption is eliminated. I* $^{*}$
The dangers attendant on intravenous therapy have been pointed out by many authors. Robinson et al. (1924) stated that intravenous digitalization should only be used after an adequate appreciation of these and especially where digitalis seems to be urgently required. Clarke (1924) spoke against its intravenous use. Luten (1937) expressed no enthusiasm for intravenous therapy, but stated that when the method had to be employed, the slow injection of ouabain, well diluted and in conservative amount, probably afforded the least objectionable procedure. Fishberg (1940) stated that the hope of attaining success by the intravenous administration of digitalis to patients in whom large doses of the drug by mouth failed to produce improvement had always proved illusory in his experience. The intravenous use of strophanthin or digitalis, since the introduction of the purified glucosides, has more recently been advised in urgent cases by many authorities including Lewis (1937), Parkinson (1940), and White (1944).

Methods of assay, chemical analysis, and the isolation of pure glucosides have rendered digitalis therapy simpler and safer, but the exact amount required in an individual case has still to be determined by trial and error in a manner similar to that employed by Withering. Its effect in reducing the heart rate in auricular fibrillation, long known to parallel closely its beneficial effects and to be responsible for many of them, provides a method for the measurement of clinical benefit-not perfect, but the best available. Gavey and Parkinson (1939) discussing the effects of digitalis on patients with auricular fibrillation said that most of those with slowing of the heart rate also showed clinical benefit, but in the absence of slowing there was no benefit. When the effect of oral and intravenous administration of the digitalis preparations was compared (Table VIII) preparations given intravenously gave more consistent results within four hours than when given orally. The difference, although significant, was not great, and was partly due to the fact that some of the oral doses were too small for particular patients. The impossibility of forecasting the correct dosage in advance is the chief difficulty in reaching a satisfactory comparison of the oral and intravenous methods of administration.

Strophanthin in a dose of $1 / 100$ gr. gave inconstant and poor results. In a dose of $1 / 60 \mathrm{gr}$. it produced a good effect in three out of four cases, but this is much larger than the maximum safe dose in the view of most writers. Strophosid gave better results than strophanthin; it produced a good effect in five out of nine cases, a rapid action being seen in three cases. It worked better than strophanthin twice, and as well once, in the three cases in which 
TABLE VIII

The Effectiveness of Digitalis Preparations in Different Dosage, and given by Mouth or INTRAVENOUSLY

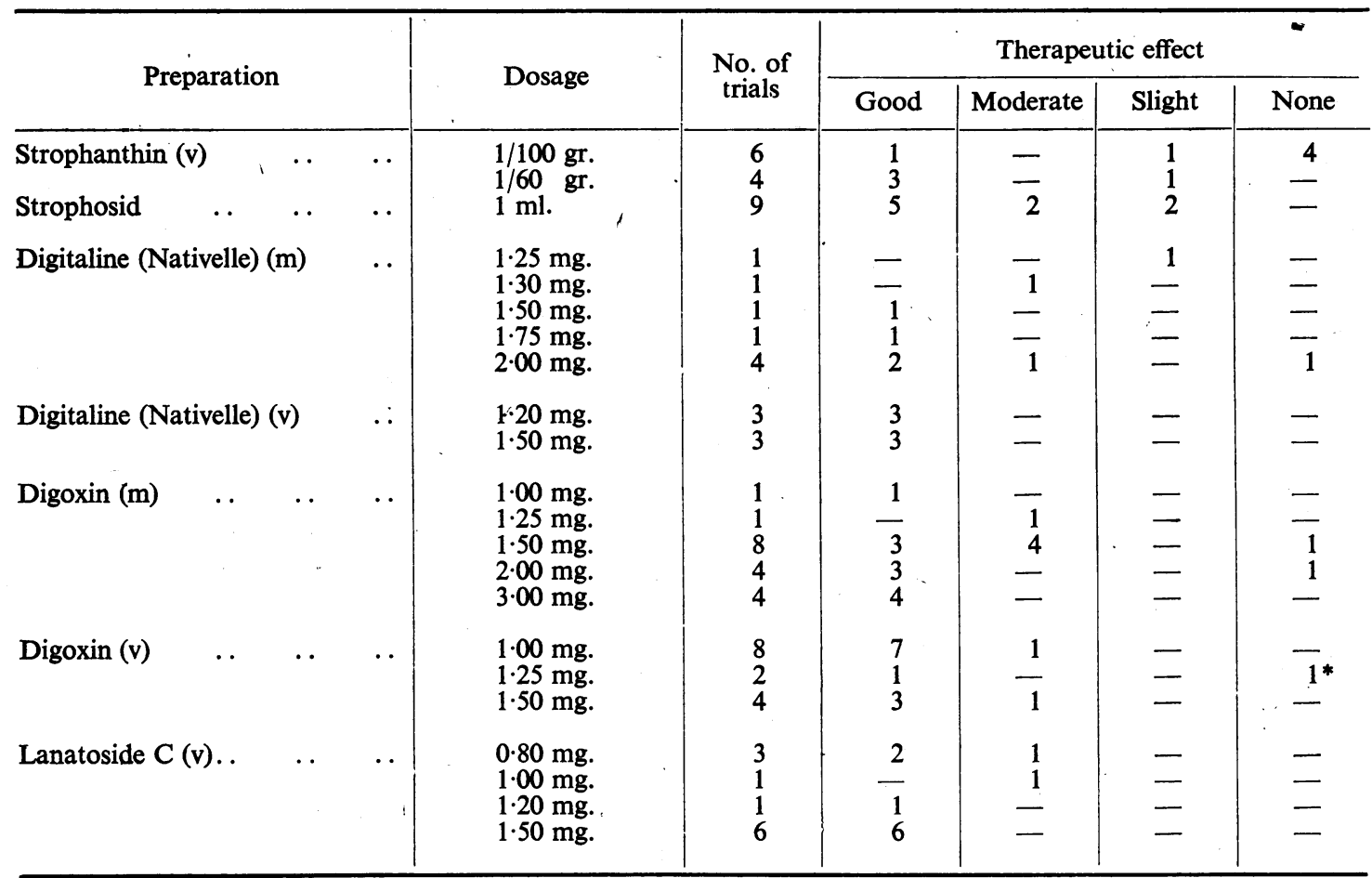

* Toxic effect.

the drugs were compared. Yet, it did not produce the consistent results obtained from digitalis preparations, and we have found no justification for the continued use of strophanthin or strophosid.

Digitaline (Nativelle) by mouth was somewhat inconstant in its action in the dosage tried. It seemed that the doses used by us were too small, and this is in accordance with the view of Stewart (1945) who regarded $2.0 \mathrm{mg}$. as an average dose. In the few cases in which the effect of the intravenous and oral administration of the drug was compared, no support could be found for the contention that it is completely absorbed (Gold et al. 1941 and 1942). Intravenously, however, it produced consistently' good effects within two hoürs in a dose of 1.2 or $1.5 \mathrm{mg}$., and compared satisfactorily with both digoxin and lanatoside $\mathrm{C}$. A more rapid effect, namely, within the first hour, was only seen once in six cases, and therefore less often than with the other two preparations.

Digoxin by mouth did not produce consistent results in a dose less than $2.0 \mathrm{mg}$. A good effect was seen in all four cases who received $3.0 \mathrm{mg}$., and no toxic effect was seen with this dose. It would appear that a dose of at least $2.0 \mathrm{mg}$. by mouth is advisable if a full digitalis effect is required within four hours. A much more rapid effect was seen when the drug was given intravenously. In the fourteen cases in which the two methods of administration were compared, a better effect was seen in all during the second hour with intravenous administration. Intravenously, digoxin produced a good effect in the great majority of cases and a very rapid effect was seen in more than half. When compared with intravenous lanatoside $C$, however, it was not so effective in six out of eight cases. Lanatoside $\mathrm{C}$ intravenously in a dose of $1.5 \mathrm{mg}$. produced a good effect in all of six cases to which it was given. Of the ten cases who received this drug a very rapid effect was seen in seven. Thus, it gave better results than any other preparations when used intravenously, but only slightly better than digoxin.

Where a digitalis effect is required within an hour intravenous administration is the method of choice, and the attendant risks of such therapy are small. These investigations showed that lanatoside $\mathbf{C}$ and 
digoxin were the best preparations for intravenous use; the slightly better results obtained with lanatoside $\mathrm{C}$ are within the limits of experimental error. With oral administration the results obtained with different dosage have naturally varied, but a full effect within four hours can be ensured if an appropriate dose of digoxin is used.

\section{CONCLUSIONS}

Strophanthin and a number of digitalis preparations were submitted to a clinical trial in 20 patients with auricular fibrillation and heart failure with the object of discqvering the best means of bringing about a digitalis effect quickly (rapid digitalization).

Digoxin and lanatoside $\mathrm{C}$ proved to be the best and digitaline (Nativelle) was scarcely less efficient.

Should it be necessary to induce digitalization within two hours, digoxin as $1.5 \mathrm{mg}$. intravenously or as 2.0 to $3.0 \mathrm{mg}$. orally, and lanatoside $C$ as 1.5 mg. intravenously only, can best accomplish it.

To establish adequate digitalization within four hours digoxin as $2.0 \mathrm{mg}$. by mouth is an effective method.

As it is seldom necessary to obtain a digitalis effect in less than two to three hours, and as intravenous medication may be less convenient, digoxin as 2.0 to $3.0 \mathrm{mg}$. by mouth is generally the best way to induce rapid digitalization.

We wish to thank Dr. Donald Hunter and Dr. A. E. Clark-Kennedy for allowing us to treat four patients under their care. Sir John Parkinson, Physician to the Cardiac Department, has given us advice on the preparation of this paper.

\section{REFERENCES}

Clarke, N. C. (1924). Amer. J. med. Sci., 168, 201.

Cushny, A. R. (1925). The Action and Uses in Medicine of Digitalis and its Allies. London.

Eggleston, C. (1915). Arch. intern. Med., 16, 1.

and Wyckoff, J. (1922). Ibid., 30, 133.

Evans, W. (1940). Brit. Heart J., 2, 51.

Fishberg, A. M. (1940). Heart Failure. 2nd ed., London.

Fraenkel, A., and Schwarz, G. (1907). Arch. exper. Path. Pharm., 57, 79.

Fraser, F. R. (1922). Lancet, $2,703$.

Gavey, C. J., and Parkinson, J. (1939). Brit. Heart J., $1,27$.

Gold, H., and Cattell, McK. (1941). Science, 93, 197.

$\longrightarrow$, Modell, W., Kwit, N. T., Kramer, M. L., and Zahm, W. (1944). J. Pharmacol., 82, 187.

$\longrightarrow$, and De Graff, A. C. (1930). J. Amer. med. Assoc., 95, 1237. and Travell, J. (1941). J. Pharmacol., 72, 41.

_-, Kwit, N. T., Cattell, McK., and Kramer, M. (1941). Ibid., 72, 17.

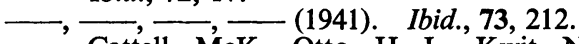

$\longrightarrow$ Cattell, McK., Otto, H. L., Kwit, N. T., and Kramer, M. D. (1942). Ibid., 75, 196.

—, Kwit, N. T., Cattell, McK., and Travell, J. (1942). J. Amer. med. Assoc., 119, 928.
Haag, H. B., and Hatcher, R. A. (1929). Amer. J. Pharmacol., 101, 474.

Katz, L. N., and Wise, W. (1945). Amer. Heart J., 30, 125.

Levy, R. L., and Mackie, T. T. (1927). J. Amer. med. Assoc., 89, 432.

-, Bruenn, H. G., and Ellis, S. L. (1932). Amer. Heart J., 8, 226.

Lewis, T. (1937). Diseases of the Heart. 2nd ed., London.

Luten, D. (1937). The Clinical Use of Digitalis. London. Lyon, D. M., and Gilchrist, A. R. (1927). J. Pharmacol., 31, 319.

Mackenzie, J. (1914). Diseases of the Heart. 3rd ed., Oxford.

Marvin, H. M. (1928). New Eng. J. Med., 199, 547.

Parkinson, J. (1940). Index of Treatment. 12th ed. Edited by Sir Robert Hutchinson. London.

Robinson, G. C. (1920). Amer. J. Med. Sci., 159, 121.

-, White, P. D., Eggleston, C., and Hatcher, R. A. (1924). J. Amer. med. Assoc., 83, 504.

Stewart, H. (1945). New York State J. Med., 45, 1676.

Wenckebach, K. F. (1910). Brit. med. J., 2, 1600.

White, P. D. (1944). Heart Disease. 3rd ed., New York.

$\longrightarrow$, and Morris, R. E. (1918). Arch. intern. Med., 21, 740 .

Wyckoff, J., and Goldring, W. (1927). Ibid., 39, 488. 